\title{
The Inhibition of RasGRF2, But Not RasGRF1, Alters Cocaine Reward in Mice
}

\author{
Rick E. Bernardi, ${ }^{1 \star}$ Anastasia Olevska, ${ }^{1 *}$ - Ilaria Morella, ${ }^{2,3}$ Stefania Fasano, ${ }^{2,3}$ Eugenio Santos, ${ }^{4}$ Riccardo Brambilla, ${ }^{2,3}$ \\ and $\odot$ Rainer Spanagel ${ }^{1}$ \\ ${ }^{1}$ Institute of Psychopharmacology, Central Institute of Mental Health, Medical Faculty Mannheim, University of Heidelberg, Mannheim 68159, Germany, \\ ${ }^{2}$ Neuroscience and Mental Health Research Institute, Cardiff University, Cardiff CF24 4HQ, United Kingdom, ${ }^{3}$ Cardiff University, School of Biosciences, \\ Division of Neuroscience, Cardiff CF24 4HQ, United Kingdom, and ${ }^{4}$ Centro de Investigación del Cáncer-Instituto de Biología Molecular y Celular del Cáncer \\ (CSIC-Universidad de Salamanca) and CIBERONC, Salamanca, Spain, 37007
}

Ras/Raf/MEK/ERK (Ras-ERK) signaling has been implicated in the effects of drugs of abuse. Inhibitors of MEK1/2, the kinases upstream of ERK1/2, have been critical in defining the role of the Ras-ERK cascade in drug-dependent alterations in behavioral plasticity, but the Ras family of small GTPases has not been extensively examined in drug-related behaviors. We examined the role of Ras Guanine Nucleotide Releasing Factor 1 (RasGRF1) and 2 (RasGRF2), upstream regulators of the Ras-ERK signaling cascade, on cocaine selfadministration (SA) in male mice. We first established a role for Ras-ERK signaling in cocaine SA, demonstrating that pERK1/2 is upregulated following SA in C57BL/6N mice in striatum. We then compared RasGRF1 and RasGRF2 K0 mouse lines, demonstrating that cocaine SA in RasGRF2 K0 mice was increased relative to WT controls, whereas RasGRF1 K0 and WT mice did not differ. This effect in RasGRF2 mice is likely mediated by the Ras-ERK signaling pathway, as pERK1/2 upregulation following cocaine SA was absent in RasGRF2 KO mice. Interestingly, the lentiviral knockdown of RasGRF2 in the NAc had the opposite effect to that in RasGRF2 K0 mice, reducing cocaine SA. We subsequently demonstrated that the MEK inhibitor PD325901 administered peripherally prior to cocaine SA increased cocaine intake, replicating the increase seen in RasGRF2 K0 mice, whereas PD325901 administered into the NAc decreased cocaine intake, similar to the effect seen following lentiviral knockdown of RasGRF2. These data indicate a role for RasGRF2 in cocaine SA in mice that is ERK-dependent, and suggest a differential effect of global versus site-specific RasGRF2 inhibition.

Key words: cocaine; extracellular signal-regulated kinase; histone h3; RasGRF1; RasGRF2; self-administration

Significance Statement

Exposure to drugs of abuse activates a variety of intracellular pathways, and following repeated exposure, persistent changes in these pathways contribute to drug dependence. Downstream components of the Ras-ERK signaling cascade are involved in the acute and chronic effects of drugs of abuse, but their upstream mediators have not been extensively characterized. Here we show, using a combination of molecular, pharmacological, and lentiviral techniques, that the guanine nucleotide exchange factor RasGRF2 mediates cocaine self-administration via an ERK-dependent mechanism, whereas RasGRF1 has no effect on responding for cocaine. These data indicate dissociative effects of mediators of Ras activity on cocaine reward and expand the understanding of the contribution of Ras-ERK signaling to drug-taking behavior.

\section{Introduction}

The extracellular signal-regulated kinases (ERK) cascade (Ras/ Raf/MEK/ERK; Ras-ERK) couples activity at cell surface recep-

Received May 3, 2018; revised May 17, 2019; accepted June 4, 2019.

Author contributions: R.E.B., A.O., I.M., S.F., E.S., R.B., and R.S. designed research; R.E.B., A.O., and I.M. performed research; R.E.B., A.O., I.M., R.B., and R.S. analyzed data; R.E.B. wrote the first draft of the paper; R.E.B. wrote the paper; A.O., I.M., S.F., E.S., R.B., and R.S. edited the paper.

R.E.B. and R.S. were supported by Deutsche Forschungsgemeinschaft Reinhart-Koselleck Award SP 383/5-1, ERANET COCADDICT, and BMBF (01ZX1909-SysMedSUDs). I.M. and R.B. were supported by grants from Life Science Research Network Wales and Wellcome Trust (DEFINE). I.M. was supported by fellowships from The Waterloo Foundation and Deutscher Akademischer Austauschdienst (Research Stays for University Academics and Scientists, tors with the activation of transcription factors and subsequent gene expression (Grewal et al., 1999; Mazzucchelli and Brambilla, 2000). Largely known for its regulation of cell proliferation, differentiation, and survival (Roberts and Der, 2007; Mandalà et al.,

2018). Portions of this manuscript were included in the PhD dissertation of co-first author A.0. (Olevska, 2016). We thank Elizabeth Röbel for invaluable technical assistance.

The authors declare no competing financial interests.

*R.E.B., A.O., and I.M. share 1st authorship.

Correspondence should be addressed to Rick E. Bernardi at rick.bernardi@zi-mannheim.de.

https://doi.org/10.1523/JNEUROSCI.1120-18.2019

Copyright $\odot 2019$ the authors 
2014), the Ras-ERK pathway also plays a critical role in LTP and memory formation (Brambilla et al., 1997; Jin and Feig, 2010), as well as reinforcement and enduring drug-dependent plasticity (Valjent et al., 2000; Ferguson et al., 2006; Girault et al., 2007). Indeed, this pathway has been implicated in the acute and chronic effects of a variety of drugs of abuse, most notably cocaine and other psychostimulants (Valjent et al., 2000; Lu et al., 2005; Miller and Marshall, 2005).

The majority of studies defining the role of the Ras-ERK pathway in drug-mediated behaviors have been achieved using inhibitors of MEK1/2, the kinases upstream of ERK1/2, while the Ras family of small GTPases has not been extensively examined. Ras family GTPases link extracellular signals to distinct intracellular signaling cascades by switching from an inactive GDP-bound state to an active GTP-bound state, each of which recognizes a distinct set of effector proteins and thereby allows Ras to function as a molecular switch (Takai et al., 2001; Cox and Der, 2010). The activation state of Ras proteins is controlled by two types of regulatory proteins. Guanine nucleotide exchange factors catalyze the release of bound GDP, thus allowing activating GTP to replace it. GTPase activating proteins promote the ability of Ras to hydrolyze GTP to GDP (Boguski and McCormick, 1993; Pamonsinlapatham et al., 2009). Multiple mammalian families of guanine nucleotide exchange factors regulate the Ras activation cycle (Cox and Der, 2010). Particularly important with respect to the Ras-ERK pathway in neuronal signaling are two members of the Ras guanine nucleotide releasing factor (RasGRF) family of guanine nucleotide exchange factors, RasGRF1 and RasGRF2, that allow certain neurotransmitter receptors to activate Ras in a $\mathrm{Ca}^{2+} /$ calmodulin-dependent manner (Farnsworth et al., 1995).

RasGRF1 has been shown to play a role in the neuronal and behavioral responses to both psychostimulants and alcohol (Zhang et al., 2007; Fasano et al., 2009; Parelkar et al., 2009; Ben Hamida et al., 2012). For example, RasGRF1 KO mice show a decrease in the phosphorylation of ERK (pERK) in the ventral striatum (VS) in response to cocaine, whereas RasGRF1 overexpressing mice show an increased pERK in the VS following cocaine, as well as decreased and increased, respectively, cocainemediated locomotor sensitization and conditioned place preference (CPP) (Fasano et al., 2009). The extent to which RasGRF2 may be involved in drug-mediated behaviors has to date been primarily restricted to alcohol studies. A single-nucleotide polymorphism in the gene encoding RasGRF2 has been associated with alcohol consumption (Schumann et al., 2011) and further linked to alcohol-related reward anticipation (Stacey et al., 2012) and binge drinking in male adolescents (Stacey et al., 2016), and RasGRF2 KO mice demonstrated a loss in alcohol-induced dopamine increase in the NAc and reduction in alcohol drinking (Stacey et al., 2012). However, it is unclear whether the involvement of RasGRF2 extends to other drugs of abuse.

The purpose here was to better characterize the role of the Ras-ERK pathway by direct comparison of the contribution of RasGRF1 and RasGRF2 to cocaine-mediated behaviors. We first established a role for the Ras-ERK pathway in cocaine selfadministration (SA) by performing immunohistochemistry for pERK1/2, as well as the phosphorylation of (Ser10)-acetylated (Lys14) histone H3 (pAcH3), a nuclear ERK substrate that has demonstrated involvement in drug-induced neuroadaptations in both rodents and humans (Brami-Cherrier et al., 2009; DamezWerno et al., 2016; Papale et al., 2016). We then performed SA in RasGRF1 and RasGRF2 KO mice and WT littermate controls, followed by further pERK and pAcH3 analysis. We also performed site-specific lentiviral knockdown of RasGRF1 and RasGRF2 in mice in the NAc, as well as in the dorsal striatum (DS). Finally, we examined the effects of both the peripheral and site-specific inhibition of MEK1/2 on cocaine SA. Our experiments indicate a role for RasGRF2, but not RasGRF1, in cocaine SA in mice.

\section{Materials and Methods}

Animals

C57BL/6N mice (Charles River) and male RasGRF1 (Brambilla et al., 1997) and RasGRF2 (Fernández-Medarde et al., 2002) KO mice and their WT littermate controls were single-housed in a temperature-controlled $\left(21^{\circ} \mathrm{C}\right)$ environment maintained on a $12 \mathrm{~h}$ light-dark cycle (lights on at 6:00 A.M.). Food and water were available ad libitum. All experiments were performed in accordance with European Union guidelines on the care and use of laboratory animals and were approved by the local animal care committee. All behavioral testing was conducted during the light phase between 0800 and $1700 \mathrm{~h}$.

\section{Drugs}

Cocaine hydrochloride (Sigma-Aldrich) was dissolved in physiological saline $(0.9 \% \mathrm{NaCl})$ for $0.50 \mathrm{mg} / \mathrm{kg} / 14 \mu \mathrm{l}$ infusion for SA (Bernardi et al., 2017). PD325901 (Sigma-Aldrich) was dissolved in 100\% DMSO and diluted to a $20 \%$ DMSO solution with sterile $0.9 \% \mathrm{NaCl}$ for intraperitoneal injection of $10 \mathrm{mg} / \mathrm{kg}(10 \mathrm{ml} / \mathrm{kg})$. For intracranial administration, PD325901 (Carbosynth) was dissolved in 100\% DMSO and diluted to a $0.002 \%$ DMSO solution with sterile $0.9 \% \mathrm{NaCl}$ for intracranial injection of $5 \mathrm{ng} / 0.5 \mu \mathrm{l} / \mathrm{side}$. This dose was determined using a comparison of its $\mathrm{IC}_{50}$ with that of other MEK inhibitors commonly used for intracranial injection. The vehicle for all PD325901 experiments consisted of an identical percentage DMSO solution as that used for the drug.

\section{Lentiviral vector ( $L V)$ production}

The LV-RasGRF1-shRNA, LV-RasGRF2-shRNA, and LV-scrambledshRNA were constructed and prepared as previously described (Bido et al., 2015). Briefly, expression plasmids for Ras-GRF1 and Ras-GRF2 RNA interference were obtained from a commercial source (OriGene). The following sequences were used as shRNA inserts against RasGRF1 and RasGRF2, respectively: GACGGCCTGGTCAACTTCTCCAAGAT GAG and TAATGCAGAAGTACATTCATCTAGTTCAG. The company provided all scrambled control sequences. The shRNA gene-specific expression cassettes (U6-shRNA cassette) were cloned into the pCCLsin.PPT.hPGK.eGFP.PRE lentiviral construct. VSV-pseudotyped thirdgeneration LVs were produced as previously described (Indrigo et al., 2010; Papale and Brambilla, 2014). Western blots demonstrating knockdown of both RasGRF1 and RasGRF2 proteins both in vitro and in vivo in striatal cells have been shown previously (Bido et al., 2015).

\section{Apparatus and procedures}

Cocaine SA. Cocaine SA was assessed in 12 operant chambers (Med Associates) housed in light- and sound-attenuating cubicles. Each chamber $(24.1 \times 20.3 \times 18.4 \mathrm{~cm})$ is equipped with two levers (left and right), a food dispenser, and a drug delivery system connected via infusion pump (PHM-100, Med Associates) located outside the cubicle. Operant chambers were controlled using Med-PC IV (Med Associates) software. Mice first underwent lever training with $14 \mathrm{mg}$ sweetened food pellets (TestDiet), as previously described (Bernardi and Spanagel, 2013). Following lever training, mice were implanted with an indwelling intravenous catheter (made in-house) into the jugular vein. Catheter patency was maintained with $0.15 \mathrm{ml}$ heparinized saline $(100 \mathrm{IU} / \mathrm{ml})$ containing Baytril $(0.7 \mathrm{mg} / \mathrm{ml})$ administered daily throughout the experiment. After $3 \mathrm{~d}$ recovery, mice underwent daily $1 \mathrm{~h}$ cocaine SA for 7 consecutive days. Cocaine $(0.50 \mathrm{mg} / \mathrm{kg} / 14 \mu \mathrm{l}$ infusion $)$ delivery was contingent upon pressing on the active lever under an FR2 schedule of reinforcement (unless otherwise specified) and paired with the $20 \mathrm{~s}$ presentation of a blinking light stimulus (conditioned stimulus), which also served as a timeout period, during which lever presses were not reinforced. For all experiments, presses on the inactive lever were recorded but had no scheduled consequence.

Immunohistochemistry. Immunohistochemistry was performed following the protocol described by Papale et al. (2016). Free-floating sec- 
tions were rinsed in TBS and then incubated for $15 \mathrm{~min}$ in a quenching solution containing $3 \% \mathrm{H}_{2} \mathrm{O}_{2}$ and $10 \%$ methanol. One hour after blocking in $5 \%$ normal goat serum and $0.1 \%$ Triton $\mathrm{X}-100$, sections were incubated overnight at $4^{\circ} \mathrm{C}$ with anti-phospho-p44/42 MAP kinase (Thr202/Tyr204) (1:1000, Cell Signaling Technology, catalog \#4370L, RRID:AB_231511), anti-phospho (Ser10)-acetylated (Lys14) histone H3 (1:500, Millipore, catalog \#07-081, RRID:AB_310366), or anti-GFP antibody (1:500, Invitrogen, catalog \#A11122, RRID:AB_221569). The next day, slices were rinsed in TBS and incubated with biotinylated goat antirabbit IgG (1:200, Vector Laboratories, catalog \#BA-1000, RRID: $\left.A B \_2313606\right)$ for $2 \mathrm{~h}$ at room temperature. Detection of the bound antibodies was performed using a standard peroxidase-based method (ABC-kit, Vectastain, Vector Labs), followed by incubation with DAB and $\mathrm{H}_{2} \mathrm{O}_{2}$ solution. Images were acquired from the DS and VS with a bright field microscope (Leica Microsystems, DM2000LED Macro/micro imaging system) at $20 \times$ magnification. Neuronal quantification was performed using ImageJ software. The total number of pERK1/2- and pAcH3-positive cells was counted in the DS and VS in 2 consecutive rostral sections per mouse.

Lentivirus microinjections. Mice were anesthetized by isoflurane ( $4 \%$ for induction, $1 \%$ for maintenance), secured in a stereotaxic frame (David Kopf Instruments), and the lentiviral vectors (LV-RasGRF1-shRNA, LV-RasGRF2-shRNA, and LV-scrambled-shRNA) were bilaterally injected into the NAc (AP 1.20, ML $\pm 0.90, \mathrm{DV}-4.75$, relative to bregma) or DS (AP $0.00, \mathrm{ML} \pm 2.20, \mathrm{DV}-3.30$, relative to bregma) in a volume of $0.5 \mu \mathrm{l} /$ hemisphere over $2 \mathrm{~min}$ (at a rate of $0.125 \mu \mathrm{l} / \mathrm{min}$ ). After the infusion, needles were left in place for additional $2 \mathrm{~min}$ to allow for diffusion. Mice were then sutured and allowed to recover from surgical procedures. After the completion of behavioral experiments, mice were anesthetized with isoflurane and perfused with $5 \mathrm{ml}$ ice-cold PBS and 5 $\mathrm{ml} 4 \%$ PFA in PBS; their brains were removed and kept in 4\% PFA in PBS overnight for postfixation and then transferred into $30 \%$ sucrose in PBS solution for at least $24 \mathrm{~h}$. Coronal sections $(30 \mu \mathrm{m})$ were subsequently taken at the level of the NAc or DS with a cryostat (Leica Microsystems), mounted onto polarized glass slides, and eGFP expression was imaged using fluorescent microscopy. The extension of virus spread was assessed manually based on the mouse brain atlas (Paxinos and Franklin, 2004). Animals with placements outside of the NAc or DS, with unilateral expression or extensive mechanical damage, were excluded. No distinction was made between core and shell or dorsolateral and dorsomedial striatum in terms of virus injections, due to the difficulty in targeting one region specifically in mice.

Cannula implantation and microinjections. Following food training, mice were anesthetized by isoflurane (4\% for induction, $1 \%$ for maintenance), secured in a stereotaxic frame (David Kopf Instruments), and cannulae (Plastics One) were mounted above the NAc (C235GS, double cannula, AP 1.20, ML $\pm 0.75, \mathrm{DV}-2.75$, relative to bregma) or DS (C315GS, bilateral single cannula, AP 0.00, ML \pm 2.20 , DV -1.80 , relative to bregma), secured using screws and dental cement, and dummy cannulae (C235DCS and C315DCS for NAc and DS, respectively, Plastics One) were inserted to protect the cannulae. Mice were then allowed to recover from surgical procedures for $7 \mathrm{~d}$. Dummy cannulae were removed before and replaced following daily SA sessions to habituate the animals to the handling procedure. Microinjections of PD325901 were conducted using internal cannula (C235IS and C315IS for NAc and DS, respectively, Plastics One) that extended beyond the cannula guide (2 $\mathrm{mm}$ for NAc and $1.5 \mathrm{~mm}$ for DS) in a volume of $0.5 \mu \mathrm{l} /$ hemisphere over $2 \mathrm{~min}$ (at a rate of $0.125 \mu \mathrm{l} / \mathrm{min}$ ) under isoflurane anesthesia. After the infusion, needles were left in place for an additional $2 \mathrm{~min}$ to allow for diffusion. After the completion of behavioral experiments, all mice were anesthetized with isoflurane, cannulae were injected with Coomassie blue dye, and brains were removed and flash-frozen in isopentane for placement verification. Coronal sections $(30 \mu \mathrm{m})$ were assessed as to cannula placement using the mouse brain atlas (Paxinos and Franklin, 2004). Animals with placements outside of the NAc or DS were excluded. No distinction was made between core and shell or dorsolateral and dorsomedial striatum in terms of intracranial injections, due to the difficulty in targeting one region specifically in mice.

\section{Experimental design and statistical analysis}

Statistical analyses were conducted using SPSS software (StatSoft). All SA data were performed using three-way [number of presses: genotype/ treatment (between subjects) $\times$ lever (within subjects) $\times$ day (within subjects)] or two-way ANOVAs [number of reinforcers: genotype/ treatment (between subjects) $\times$ day (within subjects)], followed by Bonferroni-corrected independent-samples $t$ tests, where indicated. Cocaine intake data following intracranial PD325901 microinjection were compared using independent-samples $t$ tests, where indicated. Immunohistochemical data in RasGRF2 KO mice and controls were conducted using a two-way ANOVA [genotype (between subjects) $\times$ treatment (between subjects)], followed by independent-samples $t$ tests, where indicated. Immunohistochemical data in all other experiments were compared using independent-samples $t$ tests, except where data were non-normal, in which a Mann-Whitney $U$ test was used (where indicated). Significance was set at $p<0.05$.

\section{Results \\ $\mathrm{pERK} 1 / 2$ and $\mathrm{pAcH} 3$ are increased in $\mathrm{C} 57 \mathrm{BL} / 6 \mathrm{~N}$ mice following cocaine $\mathrm{SA}$}

We previously showed that acute cocaine resulted in an increase in the number of pERK1/2- and pAcH3-positive cells in the VS and DS (Papale et al., 2016). Here we sought to determine the role of the Ras-ERK pathway in cocaine SA using these indicators. We first performed immunochemistry for pERK1/2- and pAcH3positive cells in the VS and DS on the seventh day of SA. C57BL/6N mice underwent cocaine $(n=5)$ or saline $(n=6) \mathrm{SA}$ (as described above), with animals killed 30 min following the first infusion achieved on day 7. Following testing, mice were anesthetized with isoflurane and transcardially perfused with PBS and 4\% PFA in PBS. Brains were removed and placed in 4\% PFA in PBS for $24 \mathrm{~h}$ for postfixation, and then transferred into $20 \%$ sucrose in PBS for at least $24 \mathrm{~h}$ and finally into $30 \%$ sucrose in PBS until processing.

\section{pERK1/2 analysis}

Following cocaine SA, C57BL/6N mice demonstrated an increase in the number of pERK1/2-positive cells in response to cocaine on day 7 relative to saline controls in both the VS and DS. Figure $1 A$ shows the mean ( \pm SEM) number of pERK1/2-positive cells in the VS following cocaine or saline SA in C57BL/6N mice. A Mann-Whitney $U$ test revealed that distributions of the number of pERK1/2-positive cells in the VS in animals that underwent cocaine and saline SA differed significantly $(U<0.0005, Z=$ $-2.7, p=0.004)$. Figure $1 B$ shows the mean ( \pm SEM) number of pERK1/2-positive cells in the DS following cocaine or saline SA in C57BL/6N mice. An independent-samples $t$ test revealed that animals that underwent cocaine SA demonstrated a significant increase in the number of pERK1/2-positive cells in the DS relative to saline controls $\left(t_{(4.6)}=4.8, p=0.006\right)$. Figure $1 C$ shows representative slices of pERK1/2-positive cells from the VS and DS of C57BL6N mice that underwent cocaine or saline SA.

\section{pAcH3 analysis}

Following cocaine SA, C57BL/6N mice demonstrated an increase in the number of pAcH3-positive cells in response to cocaine on day 7 relative to saline controls in both the VS and DS. Figure $1 D$ shows the mean $( \pm$ SEM) number of pAcH3-positive cells in the VS following cocaine or saline SA in C57BL/6N mice. An independent-samples $t$ test revealed that animals that underwent cocaine SA demonstrated a significant increase in the number of pAcH3-positive cells in the VS relative to saline controls $\left(t_{(5.0)}=\right.$ $5.3, p=0.003)$. Figure $1 E$ shows the mean $( \pm$ SEM) number of pAcH3-positive cells in the DS following cocaine or saline SA 
in C57BL/6N mice. An independentsamples $t$ test revealed that animals that underwent cocaine SA demonstrated a significant increase in the number of $\mathrm{pAcH} 3$-positive cells in the DS relative to saline controls $\left(t_{(9)}=5.0, p=0.001\right)$. Figure $1 F$ shows representative slices of pAcH3-positive cells from the VS and DS of C57BL6N mice that underwent cocaine or saline SA.

These data suggest that pERK1/2 and $\mathrm{pAcH} 3$ are increased as a result of cocaine SA mice, suggesting that these downstream components of the Ras-ERK pathway may be critical for cocaine reward.

\section{Cocaine SA was increased in RasGRF2 KO mice but unaffected in \\ RasGRF1 mice}

To determine the contribution of RasGRF1 and RasGRF2 to cocaine SA, RasGRF1 and RasGRF2 KO lines were used. These lines have been previously demonstrated to show impaired cocaine-related behaviors and alcohol intake, respectively (Fasano et al., 2009; Stacey et al., 2012). RasGRF1 KO mice $(n=11)$ and WT littermate controls $(n=10)$, and RasGRF2 KO mice $(n=19)$ and WT littermate controls $(n=14)$, underwent SA for $7 \mathrm{~d}$ as described above.

RasGRF1 KO mice and WT controls did not differ in cocaine SA. Figure $2 A$ shows the mean ( \pm SEM) responding on the active and inactive levers during 7 daily $1 \mathrm{~h}$ sessions of cocaine SA in RasGRF1 KO mice and WT controls. A three-way ANOVA (lever $X$ day $X$ genotype) revealed significant main effects of lever $\left(F_{(1,19)}=51.8, p<0.0005\right)$, indicating a distinction between the active and inactive levers, and day $\left(F_{(2.1,39.1)}=4.8, p=0.024\right)$, but no other significant effects $(F$ values $<1)$, indicating no difference in lever responding between $\mathrm{KO}$ and WT mice. Figure $2 B$ shows the mean ( \pm SEM) number of cocaine infusions received during $7 \mathrm{~d}$ of cocaine SA in RasGRF1 KO mice and WT controls. A two-way ANOVA (day $\times$ genotype) revealed no significant effects of genotype $(F$ values $<1)$, indicating no difference in cocaine intake in RasGRF1 KO mice relative to WT controls.

RasGRF2 KO mice and WT controls differed in cocaine SA, with RasGRF2 KO mice demonstrating an increase in responding on the cocaine-associated lever and subsequent cocaine intake. Figure $2 C$ shows the mean ( \pm SEM) responding on the active and inactive levers during 7 daily $1 \mathrm{~h}$ sessions of cocaine SA in RasGRF2 KO mice and WT controls. A three-way ANOVA (lever $\times$ day $\times$ genotype $)$ revealed significant main effects of lever $\left(F_{(1,31)}\right.$ $=201.5, p<0.0005)$, indicating a distinction between the active and inactive levers, and a significant main effect of genotype $\left(F_{(1,31)}=12.8, p=0.001\right)$, and importantly, a lever $\times$ genotype interaction $\left(F_{(1,31)}=6.3, p=0.017\right)$, indicating a difference between $\mathrm{KO}$ and WT controls over $7 \mathrm{~d}$ of cocaine SA. No other effects reached significance $(F$ values $<1$, except lever $\times$ day: $\left.F_{(2.4,74.4)}=2.4, p=0.088\right)$. Independent-samples $t$ tests confirmed that RasGRF2 KO mice responded more on the active lever than control mice $\left(t_{(31)}=3.6, p=0.001\right.$; Bonferronicorrected $\alpha=0.025$ ) across days, but the two groups did not of cocaine. ${ }^{*} p<0.05,{ }^{* *} p<0.005$.
B

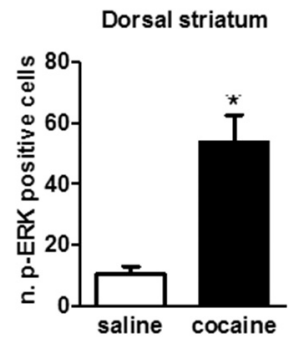

E

Dorsal striatum

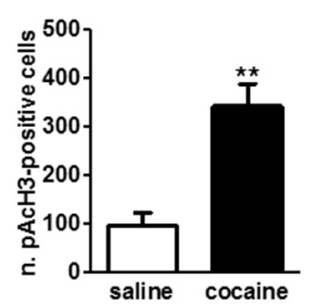

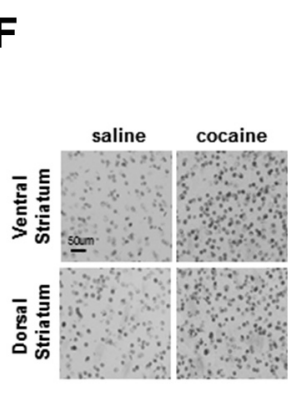

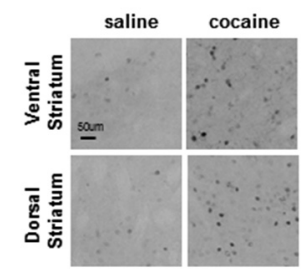

$\mathbf{F}$

C

Figure 1. Cocaine SA increased pERK1/2 and pAcH3 in C57BL/6N mice. Cocaine $(n=5)$ SA resulted in an increase in the number of pERK1/2-positive cells relative to saline controls $(n=6)$ in both the $(\boldsymbol{A})$ VS and $(\boldsymbol{B})$ DS. Data represent mean ( \pm SEM) number of controls in both the (D) VS and (E) DS. $\boldsymbol{F}$, Representative slices showing pACH3-positive cells from the VS and DS of C57BL6N mice that underwent cocaine or saline SA. Mice were killed for immunohistochemistry on day 7 of SA, 30 min following the first injection

differ on inactive lever pressing $\left(t_{(31)}=1.6, p=0.119\right.$; Bonferroni-corrected $\alpha=0.025)$, indicating a selective increase in responding on the cocaine-associated lever by RasGRF2 KO mice relative to littermate controls. Figure $2 D$ shows the mean ( \pm SEM) number of cocaine infusions received during $7 \mathrm{~d}$ of cocaine SA in RasGRF2 KO mice and WT controls. A two-way ANOVA (day $\times$ genotype) revealed a significant main effect of genotype $\left(F_{(1,31)}=9.0, p=0.005\right)$, but no other significant effects (day: $F_{(2.9,91.0)}=1.1, p=0.363$; day $\times$ genotype: $F_{(2.9,91.0)}=1.9, p=$ $0.142)$, indicating an increase in cocaine intake in RasGRF2 KO mice relative WT controls.

These findings suggest that RasGRF2, but not RasGRF1, is important in mediating cocaine reward in mice during SA. Because previous studies have demonstrated a decrease in alcohol reward in RasGRF2 KO mice (Stacey et al., 2012), these data also suggest that RasGRF2 KO results in a decrease in putative cocaine reward that, in terms of SA, is compensated for by an increase in intake.

\section{pERK1/2 and pAcH3 are inhibited in RasGRF2 KO mice following cocaine $\mathrm{SA}$}

As RasGRF2 KO in mice altered cocaine SA, immunohistochemical analyses were performed to determine whether RasGRF2 KO affected pERK1/2 and pAcH3 activation during cocaine SA, which we showed above likely mediates cocaine reward. The numbers of pERK1/2- and pAcH3-positive cells were measured in the VS and DS of RasGRF2 KO mice and WT littermate controls on the seventh day of SA. RasGRF2 KO (cocaine, $n=4$; saline, $n=5$ ) and WT controls (cocaine, $n=4$; saline, $n=5$ ) underwent cocaine or saline SA as described above, with animals killed 30 min following the first reinforcer achieved on day 7. Following testing, mice were anesthetized with isoflurane and transcardially perfused with PBS and 4\% PFA in PBS. Brains were 
A

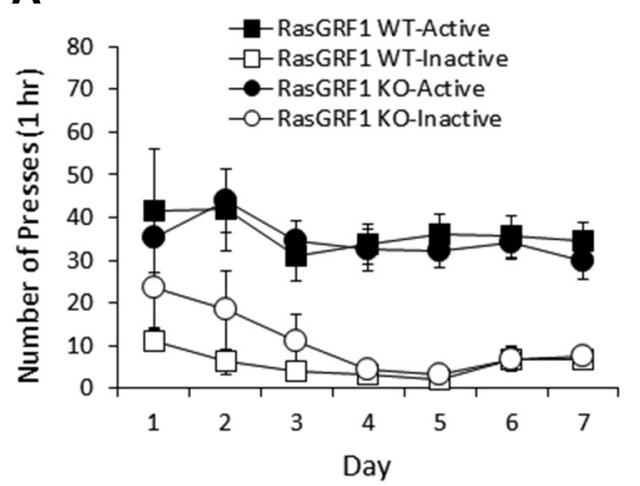

C

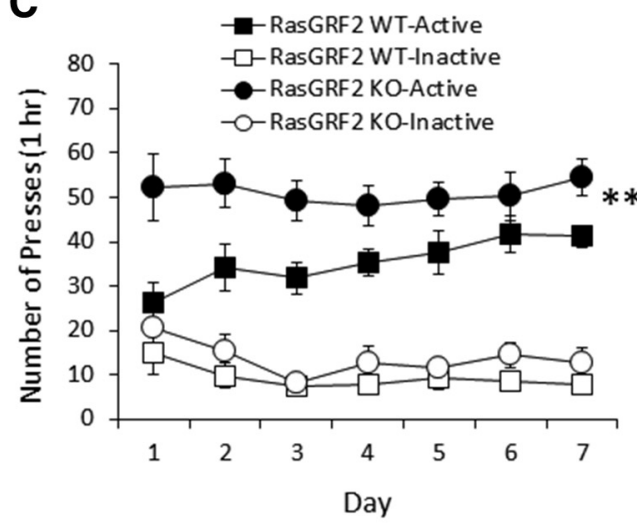

B

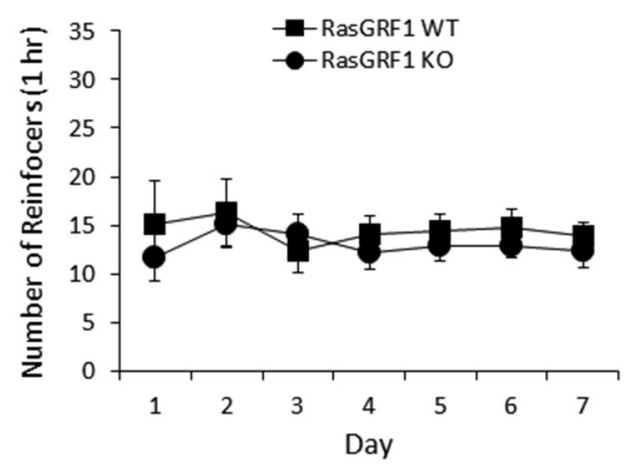

D

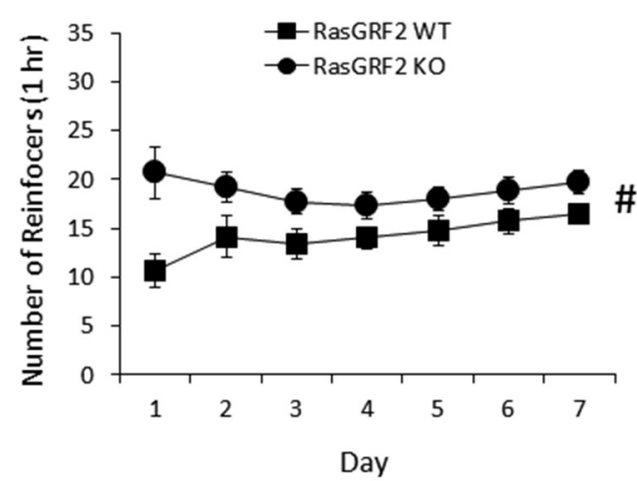

Figure 2. Cocaine SA in RasGRF1 and RasGRF2 KO mice and WT controls. A, RasGRF1 K0 mice $(n=11)$ did not differ in lever responding relative to WT controls $(n=10)$. Data represent mean ( \pm SEM) number of presses on the active and inactive levers during 7 daily $1 \mathrm{~h}$ sessions of cocaine $S A$ ( $0.50 \mathrm{mg} / \mathrm{kg} / 14 \mu \mathrm{l}$ infusion). $\boldsymbol{B}$, RasGRF1 KO mice did not differ in the number of cocaine reinforcers achieved relative to WT controls. Data represent mean ( \pm SEM) number of cocaine reinforcers achieved during 7 daily $1 \mathrm{~h}$ sessions of cocaine $S A(0.50 \mathrm{mg} / \mathrm{kg} / 14 \mu \mathrm{linfusion})$. C, RasGRF2 KO mice $(n=19)$ demonstrated an increase in responding on the cocaine-associated lever relative to WT controls $(n=14)$. Data represent mean ( \pm SEM) number of presses on the active and inactive levers during 7 daily $1 \mathrm{~h}$ sessions of cocaine $S A(0.50 \mathrm{mg} / \mathrm{kg} / 14 \mu \mathrm{l}$ infusion). D, RasGRF2 K0 mice demonstrated an increase in the number of cocaine reinforcers achieved relative to WT controls. Data represent mean ( \pm SEM) number of cocaine reinforcers achieved during 7 daily $1 \mathrm{~h}$ sessions of cocaine SA $\left(0.50 \mathrm{mg} / \mathrm{kg} / 14 \mu \mathrm{l}\right.$ infusion). ${ }^{\#} p<0.05$, main effect of genotype. **$p<$ 0.005 .

removed and placed in 4\% PFA in PBS for $24 \mathrm{~h}$ for postfixation, and then transferred into $20 \%$ sucrose in PBS for at least $24 \mathrm{~h}$, and finally into $30 \%$ sucrose in PBS until processing.

\section{pERK1/2 analysis}

Following cocaine SA, WT mice of the RasGRF2 line demonstrated an increase in the number of pERK1/2-positive cells in response to cocaine on day 7 relative to saline controls in both the VS and DS, consistent with the data from C57BL/6N mice shown in Figure 1. The increase in the number of pERK1/2-positive cells on day 7 was not present in either the VS or DS of RasGRF2 KO mice. Figure $3 A$ shows the mean ( \pm SEM) number of pERK1/2positive cells in the VS in RasGRF2 KO mice and WT controls that were killed on day 7 after cocaine or saline SA. A two-way ANOVA (genotype $\times$ treatment) of the number of pERK1/2positive cells revealed significant main effects of genotype $\left(F_{(1,14)}\right.$ $=8.2, p=0.012)$ and treatment $\left(F_{(1,14)}=6.6, p<0.022\right)$, and a significant genotype $\times$ treatment interaction $\left(F_{(1,14)}=7.0, p=\right.$ $0.019)$. An independent-samples $t$ test revealed a decrease in the number of pERK1/2-positive cells in RasGRF2 KO mice that underwent cocaine $\mathrm{SA}$, relative to WT controls $\left(t_{(6)}=2.9, p=\right.$ 0.027 ). Figure $3 B$ shows the mean ( \pm SEM) number of pERK1/ 2-positive cells in the DS in RasGRF2 KO mice and WT controls that were killed on day 7 after cocaine or saline SA. A two-way ANOVA (genotype $\times$ treatment) of the number of pERK1/2positive cells revealed significant main effects of genotype $\left(F_{(1,14)}\right.$
$=18.8, p=0.001)$ and treatment $\left(F_{(1,14)}=34.0, p<0.0005\right)$, and a significant genotype $\times$ treatment interaction $\left(F_{(1,14)}=13.3\right.$, $p=0.003)$. An independent-samples $t$ test revealed a decrease in the number of pERK1/2-positive cells in RasGRF2 KO mice that underwent cocaine SA, relative to WT controls $\left(t_{(6)}=3.6, p=\right.$ $0.011)$. Figure $3 C$ shows representative slices of $\mathrm{pERK}$-positive cells from the VS and DS of RasGRF2 KO mice and WT controls that underwent cocaine or saline SA.

\section{pAcH3 analysis}

Following cocaine SA, WT mice of the RasGRF2 line demonstrated an increase in the number of pAcH3-positive cells in response to cocaine on day 7 relative to saline controls in both the VS and DS, consistent with the data from C57BL/6N mice shown in Figure 1. The increase in the number of pAcH3-positive cells on day 7 was not present in either the VS or DS of RasGRF2 KO mice. Figure $3 D$ shows the mean $( \pm$ SEM) number of pAcH3positive cells in the VS in RasGRF2 KO mice and WT controls that were killed on day 7 after cocaine or saline SA. A two-way ANOVA (genotype $\times$ treatment) of the number of pAcH3positive cells revealed significant main effects of genotype $\left(F_{(1,14)}\right.$ $=7.9, p=0.014)$ and treatment $\left(F_{(1,14)}=22.3, p<0.0005\right)$, and a significant genotype $\times$ treatment interaction $\left(F_{(1,14)}=14.8\right.$, $p=0.002)$. An independent-samples $t$ test revealed a decrease in the number of pAcH3-positive cells in RasGRF2 KO mice that underwent cocaine SA, relative to littermate controls $\left(t_{(6)}=3.3\right.$, 
A

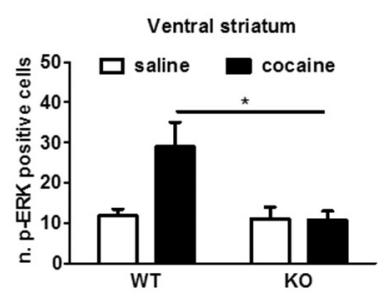

D

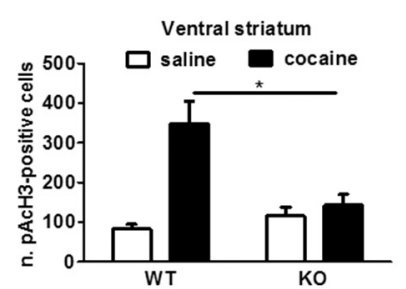

B

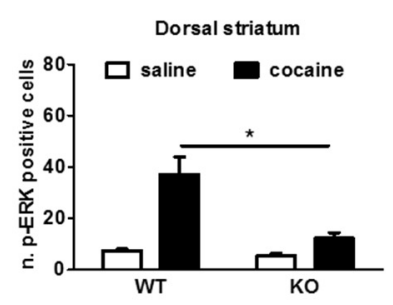

$\mathbf{E}$

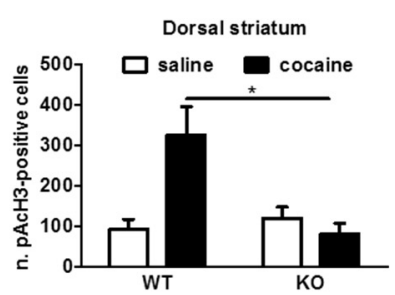

C

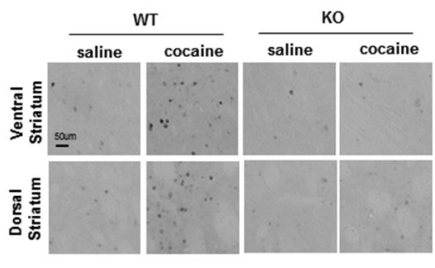

$\mathbf{F}$

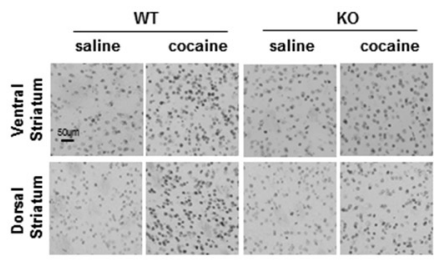

Figure 3. Cocaine SA resulted in an increase in pERK1/2 and pACH 3 in WT, but not K0, mice of the RasGRF2 line. Cocaine SA resulted in an increase in the number of pERK1/2-positive cells relative to saline controls in both the (A) VS and ( $\boldsymbol{B})$ DS in WT mice (cocaine, $n=4$; saline, $n=5$ ), an effect not present in RasGRF2 KO mice (cocaine, $n=4$; saline, $n=5$ ). Data represent mean ( \pm SEM) number of pERK1/2-positive cells in each condition. C, Representative slices showing pERK-positive cells from the VS and DS of RasGRF2 KO mice and WT controls that underwent cocaine or saline SA. Cocaine SA resulted in an increase in the number of pAcH3-positive cells relative to saline controls in both the (D) VS and (E) DS in WT mice, an effect not present in RasGRF2 K0 mice. $\boldsymbol{F}$, Representative slices showing pAcH3-positive cells from the VS and DS of RasGRF2 KO mice and WT controls that underwent cocaine or saline SA. Mice were killed for immunohistochemistry on day 7 of $S A, 30$ min following the first injection of cocaine. ${ }^{*} p<0.05$.

$p=0.017)$. Figure $3 E$ shows the mean $( \pm$ SEM) number of pAcH3-positive cells in the DS in RasGRF2 KO mice and littermate controls that were killed on day 7 after cocaine or saline SA. A two-way ANOVA (genotype $\times$ treatment) of the number of pAcH3-positive cells revealed significant main effects of genotype $\left(F_{(1,14)}=7.4, p=0.017\right)$ and treatment $\left(F_{(1,14)}=6.0, p=0.028\right)$, and a significant genotype $\times$ treatment interaction $\left(F_{(1,14)}=\right.$ $11.8, p=0.004)$. An independent-samples $t$ test revealed a decrease in the number of pAcH3-positive cells in RasGRF2 KO mice that underwent cocaine SA, relative to littermate controls $\left(t_{(6)}=3.2, p=0.019\right)$. Figure $3 F$ shows representative slices of pAcH3-positive cells from the VS and DS of RasGRF2 KO mice and WT controls that underwent cocaine or saline SA.

These data suggest that RasGRF2 mediates cocaine reward through an ERK-dependent pathway. Furthermore, these data are supportive of the hypothesis that the increase in SA demonstrated in RasGRF2 KO mice results from an inhibition of pERKmediated reward and a consequent compensatory increase in cocaine intake.

\section{Lentiviral-mediated knockdown of RasGRF2 into the NAc and DS decreased cocaine intake}

Here we sought to determine the contribution of RasGRF2 specifically in the NAc on cocaine SA in mice using lentiviralmediated knockdown of RasGRF2. Because RasGRF1 KO mice showed no difference in cocaine SA compared with littermate WT controls, we used lentiviral-mediated knockdown of RasGRF1 in the NAc as a control. Four weeks following microinjections of LV-RasGRF2-shRNA $(n=9)$ or LV-scrambled-shRNA $(n=11)$, or LV-RasGRF1-shRNA $(n=12)$ or LV-scrambledshRNA $(n=13)$, into the NAc, mice underwent $7 \mathrm{~d}$ of cocaine SA as described above. In a separate experiment, we further determined whether microinjections of LV-RasGRF2-shRNA into the DS affected cocaine SA in mice. Four weeks following microinjections of LV-RasGRF2-shRNA $(n=9)$ or LV-scrambledshRNA $(n=6)$ into the DS, C57BL/6N mice underwent $7 \mathrm{~d}$ of cocaine SA as described above. Mice from this DS group were killed immediately after the final SA session on day 7 so that, in addition to virus and placement verification, alterations in $\mathrm{pERK}$ activity during cocaine SA using immunohistochemistry could also be assessed.

Microinjections of LV-RasGRF2-shRNA into the NAc resulted in a decrease in cocaine intake during SA, relative to LVscrambled-shRNA controls. Figure $4 A, B$ shows representative viral eGFP expression images using fluorescent microscopy and DAB staining, respectively, of the LV-RasGRF2-shRNA and LVscrambled-shRNA constructs for the NAc. Figure $4 C$ shows the mean ( \pm SEM) responding on the active and inactive levers during 7 daily 1 h days of cocaine SA following NAc microinjection of LV-RasGRF2-shRNA and LV-scrambled-shRNA constructs. A three-way ANOVA (lever $\times$ day $\times$ treatment) revealed a significant main effect of lever $\left(F_{(1,18)}=61.4, p<0.0005\right)$, indicating a distinction between the active and inactive levers, but no other significant effects $\left(F\right.$ values $<1$, except lever $\times$ treatment: $F_{(1,18)}$ $=1.5, p=0.238$; lever $\times$ day: $F_{(6,108)}=2.1, p=0.063$; lever $\times$ day $\times$ treatment: $F_{(6,108)}=1.3, p=0.267$; treatment: $F_{(1,18)}=$ $2.5, p=0.132)$, indicating no significant difference in active lever-specific responding as a function of treatment. Figure $4 D$ shows the mean ( \pm SEM) number of cocaine infusions received during $7 \mathrm{~d}$ of cocaine SA. A two-way ANOVA (day $\times$ treatment) indicated a main effect of treatment $\left(F_{(1,18)}=4.8\right.$, $p=0.043)$, but no other significant effects $(F$ values $<1$ ), indicating a decrease in cocaine intake resulting from the LVRasGRF2-shRNA microinjection.

Microinjections of LV-RasGRF1-shRNA into the NAc did not affect cocaine SA, relative to LV-scrambled-shRNA controls. Figure $5 A, B$ shows representative viral eGFP expression images using fluorescent microscopy and DAB staining, respectively, of the LV-RasGRF1-shRNA and LV-scrambled-shRNA constructs for the NAc. Figure $5 C$ shows the mean $( \pm$ SEM) responding on the active and inactive levers during 7 daily $1 \mathrm{~h}$ days of cocaine SA following NAc microinjection of LV-RasGRF1-shRNA and LVscrambled-shRNA constructs. A three-way ANOVA (lever $X$ day $\times$ treatment $)$ revealed significant main effects of lever $\left(F_{(1,23)}\right.$ 
A
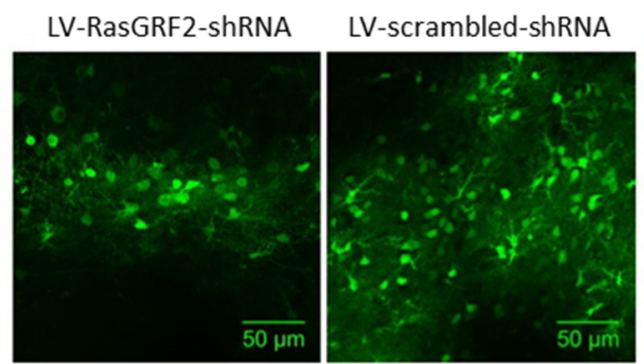

C

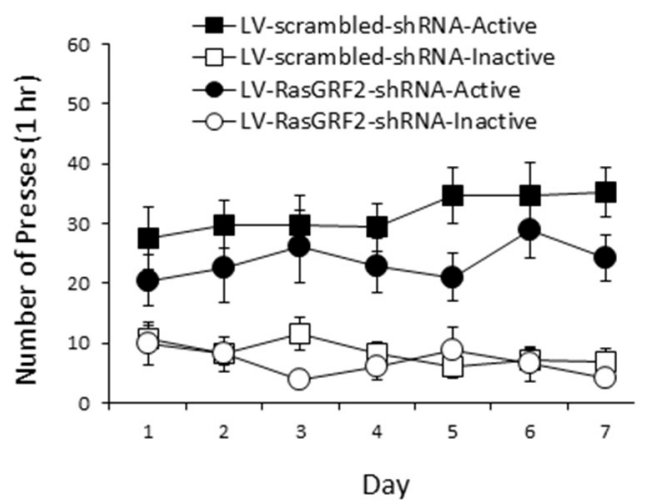

B

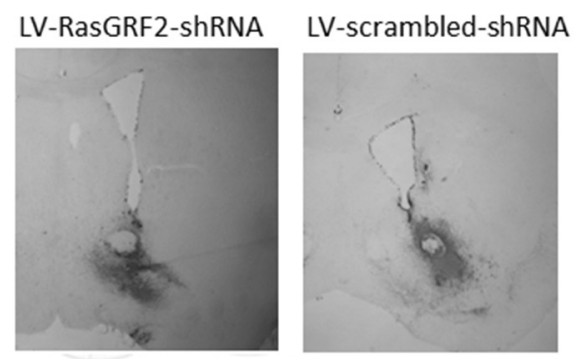

D

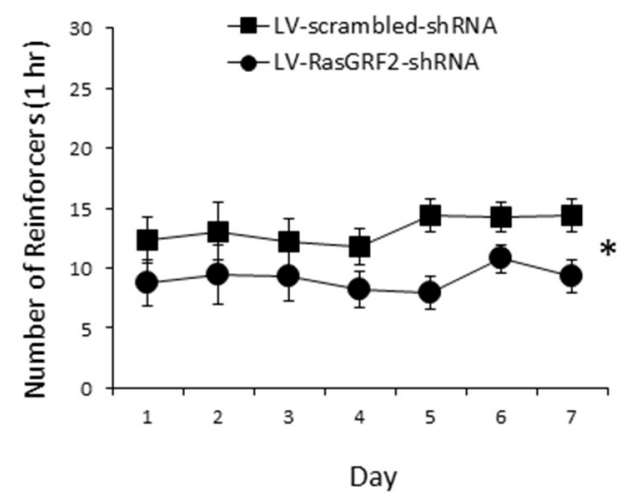

Figure 4. LV-RasGRF2-shRNA microinjected into the NAc decreased cocaine intake. $A$, Representative images of viral eGFP expression in the NAc following microinjections of RasGRF2-shRNA (left) or LV-scrambled-shRNA (right) using fluorescent microscopy. B, Representative images of viral eGFP expression in the NAc following microinjections of RasGRF1-shRNA (left) or LV-scrambledshRNA (right) using DAB staining. C, Mice microinjected with LV-RasGRF2-shRNA $(n=9)$ and LV-scrambled-shRNA $(n=11)$ did not differ significantly in lever responding. Data represent mean ( \pm SEM) number of presses on the active and inactive levers during 7 daily $1 \mathrm{~h}$ sessions of cocaine $S A(0.50 \mathrm{mg} / \mathrm{kg} / 14 \mu \mathrm{l}$ infusion). $\boldsymbol{D}$, The number of cocaine reinforcers achieved differed significantly between the groups across daily sessions, with the LV-RasGRF2-shRNA group earning less reinforcers than the LV-scrambled-shRNA group. Data represent mean ( \pm SEM) number of reinforcers achieved during 7 daily $1 \mathrm{~h}$ cocaine $S A$ sessions $\left(0.50 \mathrm{mg} / \mathrm{kg} / 14 \mu\right.$ linfusion). ${ }^{*} p<0.05$, main effect of treatment.

$=86.8, p<0.0005)$, indicating a distinction between the active and inactive levers, and a lever $\times$ day interaction $\left(F_{(3.8,87.2)}=3.0\right.$, $p=0.032)$, but no other significant effects $(F$ values $<1)$, indicating no difference in lever responding as a function of treatment. Figure $5 D$ shows the mean $( \pm$ SEM) number of cocaine infusions received during $7 \mathrm{~d}$ of cocaine SA following NAc microinjection of LV-RasGRF1-shRNA and LV-scrambled-shRNA constructs. A two-way ANOVA (day $\times$ treatment) revealed no significant effects ( $F$ values $<1$ ), indicating no difference in cocaine intake resulting from LV-RasGRF1-shRNA treatment relative to the scrambled control.

Microinjections of LV-RasGRF2-shRNA into the DS resulted in a decrease in cocaine intake during SA, relative to LVscrambled-shRNA controls. Figure $6 A, B$ shows representative viral eGFP expression images using fluorescent microscopy and DAB staining, respectively, of the LV-RasGRF2-shRNA and LVscrambled-shRNA constructs for the DS. Figure $6 C$ shows the mean ( \pm SEM) responding on the active and inactive levers during 7 daily $1 \mathrm{~h}$ days of cocaine SA following DS microinjection of LV-RasGRF2-shRNA and LV-scrambled-shRNA constructs. A three-way ANOVA (lever $\times$ day $\times$ treatment) revealed significant main effects of lever $\left(F_{(1,13)}=104.0, p<0.0005\right)$, indicating a distinction between the active and inactive levers, a main effect of treatment $\left(F_{(1,13)}=6.6, p=0.023\right)$, a lever $\times$ day interaction $\left(F_{(1.9,24.6)}=7.0, p=0.004\right)$, and only a trend toward a lever $\times$ treatment interaction $\left(F_{(1,13)}=4.5, p=0.054\right)$, but no other significant effects (day: $F_{(2.6,33.9)}=2.2, p=0.110$; day $\times$ treatment: $F_{(2.6,33.9)}=1.5, p=0.233$; lever $\times$ day $\times$ treatment: $\left.F_{(1.9,24.6)}=2.3, p=0.128\right)$, indicating no significant difference in active lever-specific responding as a function of treatment. Figure $6 D$ shows the mean ( \pm SEM) number of cocaine infusions received during $7 \mathrm{~d}$ of cocaine SA following DS microinjection of LV-RasGRF2-shRNA and LV-scrambled-shRNA constructs. A two-way ANOVA (day $\times$ treatment) revealed a main effect of treatment $\left(F_{(1,13)}=10.7, p=0.006\right)$, but no other significant effects $\left(F\right.$ values $<1$, except day: $\left.F_{(2.4,31.0)}=1.4, p=0.258\right)$, indicating a decrease in cocaine intake resulting from the LVRasGRF2-shRNA microinjection.

Immediately following the final session of cocaine SA, LVRasGRF2-shRNA mice demonstrated a decrease in the number of pERK1/2-positive cells in response relative to LV-scrambledshRNA controls in the DS. Figure 7 shows the mean $( \pm$ SEM) number of pERK1/2-positive cells in the DS in LV-RasGRF2shRNA and LV-scrambled-shRNA mice that were killed on day 7 after cocaine $S A$, as well as representative slices of pERK-positive cells from the DS of these groups. An independent-samples $t$ test revealed a decrease in the number of pERK1/2-positive cells in LV-RasGRF2-shRNA mice that underwent cocaine SA, relative to LV-scrambled-shRNA controls $\left(t_{(13)}=6.3, p<0.0005\right)$. These data are representative of the ability of LV-RasGRF2-shRNA to inhibit Ras-ERK signaling in striatal tissue as measured by pERK activation.

These data confirm a role for RasGRF2 in the NAc, as well as in the DS, in cocaine SA in mice. Because LV-RasGRF2shRNA reduced cocaine intake, in contrast to the increase in intake demonstrated in RasGRF2 KO mice, further examination is required. 
A
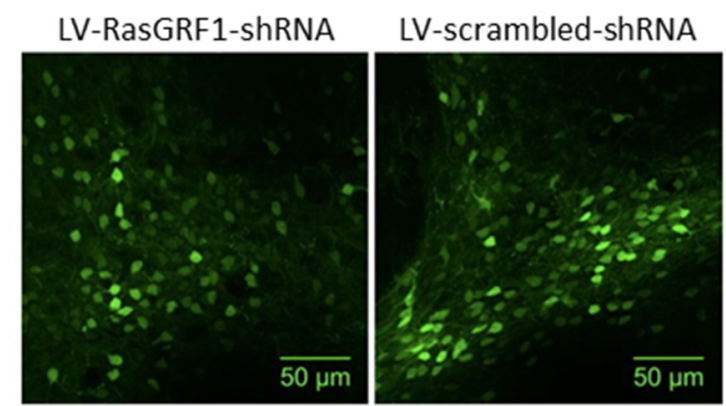

C

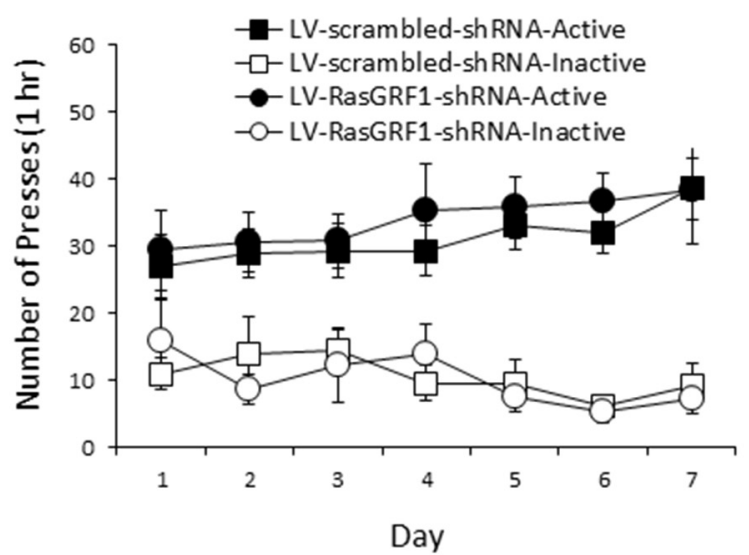

B

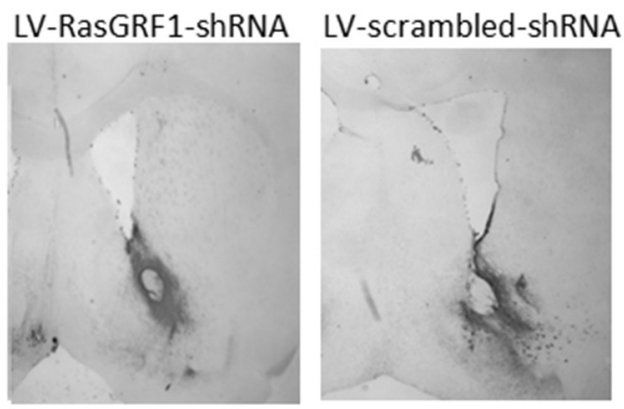

D

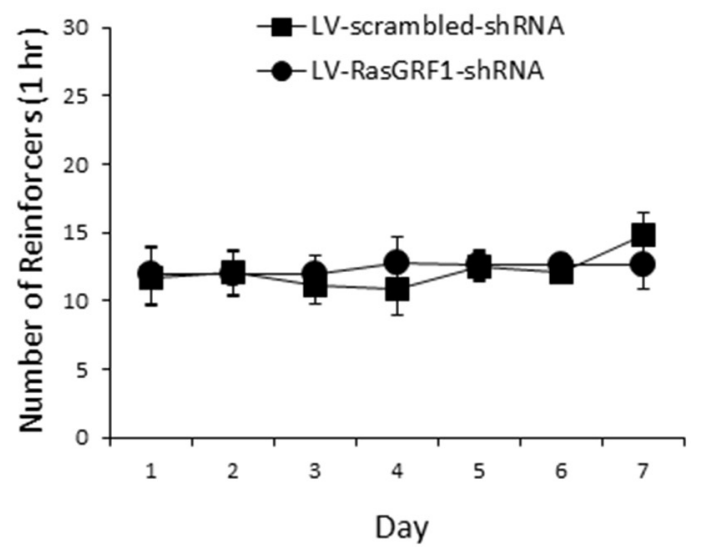

Figure 5. LV-RasGRF1-shRNA microinjected into the NAc had no effect on cocaine SA. $\boldsymbol{A}$, Representative images of viral eGFP expression in the NAc following microinjections of RasGRF1-shRNA (left) or LV-scrambled-shRNA (right) using fluorescent microscopy. B, Representative images of viral eGFP expression in the NAc following microinjections of RasGRF1-shRNA (left) or LV-scrambledshRNA (right) using DAB staining. C, Mice microinjected with LV-RasGRF1-shRNA ( $n=12$ ) and LV-scrambled-shRNA ( $n=13)$ did not differ significantly in lever responding. Data represent mean ( \pm SEM) number of presses on the active and inactive levers during 7 daily $1 \mathrm{~h}$ sessions of cocaine $S A(0.50 \mathrm{mg} / \mathrm{kg} / 14 \mu$ infusion). $D$, The number of cocaine reinforcers achieved did not differ significantly between the groups across daily sessions. Data represent mean ( \pm SEM) number of reinforcers achieved during 7 daily $1 \mathrm{~h}$ cocaine $S A$ sessions ( $0.50 \mathrm{mg} / \mathrm{kg} / 14 \mu \mathrm{linfusion}$ ).

\section{Peripheral PD325901 increased, whereas intra-NAc PD325901 decreased, cocaine SA in mice}

As our results above show, there were opposing results on cocaine intake in RasGRF2 KO mice (increased) and animals administered LV-RasGRF2-shRNA (decreased). We sought to clarify this inconsistency using the selective MEK inhibitor PD325901 administered both peripherally and site-specifically during cocaine SA. We previously showed that PD325901 crosses the bloodbrain barrier and inhibits the increased pERK1/2 and pAcH3 associated with acute cocaine (Papale et al., 2016). For peripheral PD325901 administration, C57BL/6N mice underwent $7 \mathrm{~d}$ of cocaine SA under an FR1 schedule of reinforcement following pretreatment with vehicle $(n=9)$ or PD325901 (10 mg/kg; $n=11)$ $30 \mathrm{~min}$ before the start of each daily session. For immunohistochemical confirmation of the effect of PD325901 on pERK1/2 signaling, a separate group of C57BL/6N mice underwent $7 \mathrm{~d}$ of cocaine SA under an FR2 schedule of reinforcement following pretreatment with vehicle $(n=5)$ or PD325901 $(10 \mathrm{mg} / \mathrm{kg} ; n=5)$ $30 \mathrm{~min}$ before the start of each daily session, with animals killed $30 \mathrm{~min}$ following the first infusion achieved on day 7. For intracranial injection, mice implanted with cannulae aimed at either the NAc (vehicle, $n=10$; PD325901, $n=9$ ) or DS (vehicle, $n=$ 6; PD325901, $n=7$ ) underwent 7 d of cocaine SA under an FR2 schedule of reinforcement. PD325901 was injected $30 \mathrm{~min}$ before the cocaine SA session on day 7, and mice were given additional SA sessions on days 8 and 9 .
Vehicle- and PD325901-administered mice differed in cocaine intake following peripheral administration. Figure $8 \mathrm{~A}$ shows the mean $( \pm$ SEM) responding on the active and inactive levers during 7 daily $1 \mathrm{~h}$ sessions of cocaine SA following intraperitoneal administration of PD325901 or vehicle. A three-way ANOVA (lever $\times$ day $\times$ treatment) revealed a significant main effect of lever $\left(F_{(1,18)}=62.4, p<0.0005\right)$, indicating a distinction between the active and inactive levers, a significant lever $\times$ day interaction $\left(F_{(3.3,59.1)}=4.0, p=0.01\right)$, and a main effect of treatment $\left(F_{(1,18)}=4.9, p=0.04\right)$, but no other significant effects $(F$ values $<1$, except lever $\times$ treatment: $F_{(1,18)}=3.0, p=0.10$; day $\times$ treatment: $\left.F_{(3.0,54.7)}=1.4, p=0.249\right)$. Figure $8 B$ shows the mean $( \pm$ SEM) number of cocaine infusions received during $7 \mathrm{~d}$ of cocaine SA following intraperitoneal administration of PD325901 or vehicle. A two-way ANOVA (treatment $\times$ day) revealed significant main effects of treatment $\left(F_{(1,18)}=15.8, p=\right.$ $0.001)$ and day $\left(F_{(3.0,54.4)}=3.4, p=0.024\right)$, and a significant treatment $\times$ day interaction $\left(F_{(3.0,54.4)}=3.9, p=0.013\right)$.

PD325901-treated C57BL/6N mice demonstrated a decrease in the number of pERK1/2-positive cells in response to cocaine on day 7 relative to vehicle-treated mice in both the VS and DS. Figure $8 C$ shows the mean $( \pm$ SEM) number of pERK1/2positive cells in the VS on day 7 in C57BL/6N mice administered either vehicle or PD325901 before daily SA sessions. An independent-samples $t$ test revealed that animals administered PD325901 demonstrated a significant decrease in the number of 
A
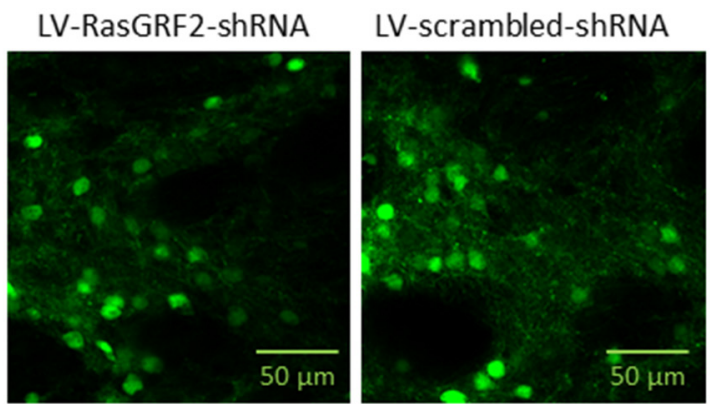

B
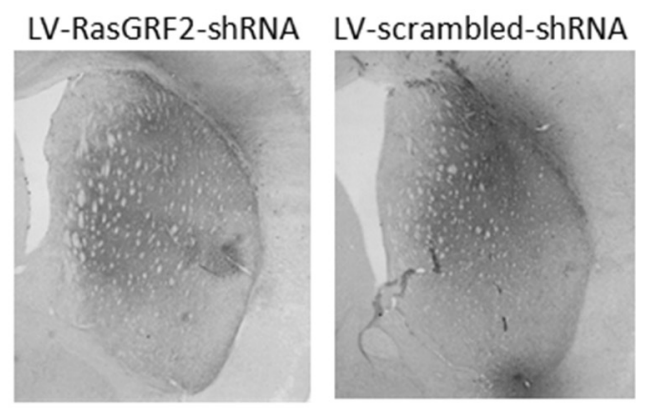

C

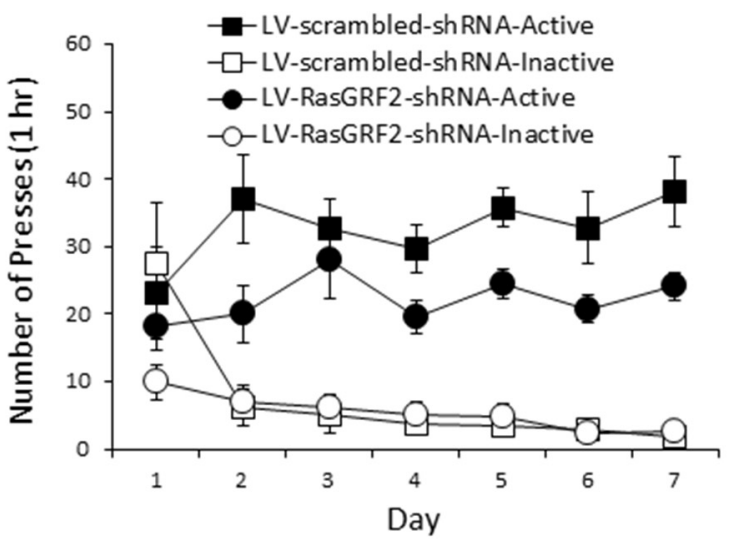

D

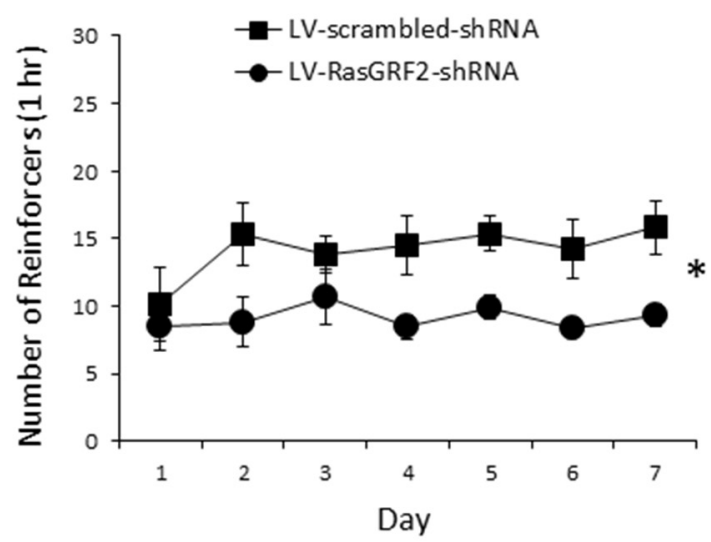

Figure 6. LV-RasGRF2-shRNA microinjected into the DS decreased cocaine intake. $\boldsymbol{A}$, Representative images of viral eGFP expression in the DS following microinjections of RasGRF2-shRNA (left) or LV-scrambled-shRNA (right) using fluorescent microscopy. B Representative images of viral eGFP expression in the DS following microinjections of RasGRF2-shRNA (left) or LV-scrambled-shRNA (right) using DAB staining. C, Mice microinjected with LV-RasGRF2-shRNA $(n=9)$ and LV-scrambled-shRNA $(n=6)$ did not differ significantly in lever responding. Data represent mean $( \pm$ SEM) number of presses on the active and inactive levers during 7 daily $1 \mathrm{~h}$ sessions of cocaine $S A(0.50 \mathrm{mg} / \mathrm{kg} / 14 \mu$ linfusion). $D$, The number of cocaine reinforcers achieved differed significantly between the groups across daily sessions, with the LV-RasGRF2-shRNA group earning less reinforcers than the LV-scrambled-shRNA group. Data represent mean ( \pm SEM) number of reinforcers achieved during 7 daily $1 \mathrm{~h}$ cocaine $S A$ sessions $\left(0.50 \mathrm{mg} / \mathrm{kg} / 14 \mu\right.$ linfusion). ${ }^{*} p<0.05$, main effect of treatment.

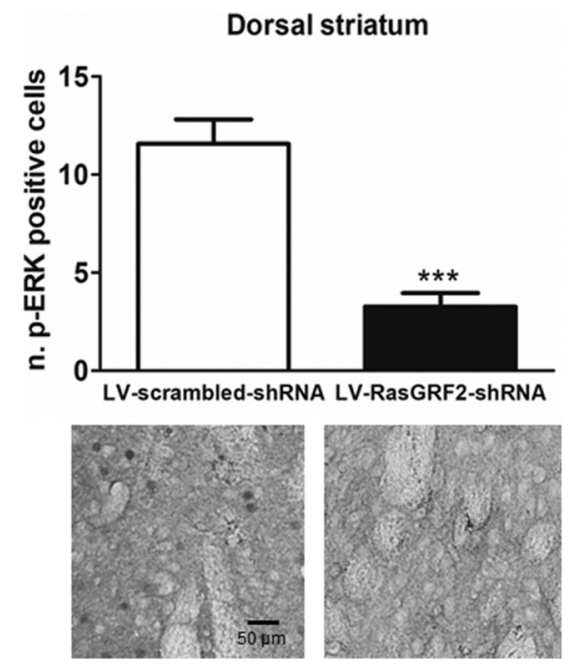

Figure 7. LV-RasGRF2-shRNA decreased pERK. LV-RasGRF2-shRNA $(n=9)$ resulted in a decrease in the number of pERK-positive cells compared with LV-scrambled-shRNA $(n=6)$ in the DS in mice killed immediately following the final cocaine SA session on day 7. Data represent mean ( \pm SEM) number of pERK1/2-positive cells in each condition, with representative slices showing pERK-positive cells from the DS of LV-RasGRF2-shRNA and LV-scrambled-shRNA below. ${ }^{* * *} p<0.0005$.
pERK1/2-positive cells in the VS relative to vehicle controls $\left(t_{(8)}\right.$ $=3.8, p=0.005)$. Figure $8 D$ shows the mean $( \pm \mathrm{SEM})$ number of pERK1/2-positive cells in the DS on day 7 in C57BL/6N mice administered either vehicle or PD325901 before daily SA sessions. An independent-samples $t$ test revealed that animals administered PD325901 demonstrated a significant decrease in the number of pERK1/2-positive cells in the DS relative to vehicle controls $\left(t_{(4.0)}=5.6, p=0.005\right)$. Figure $8 E$ shows representative slices of pERK1/2-positive cells from the VS and DS of C57BL6N mice administered vehicle or PD325901. PD325901 treatment also resulted in an increase in the number of cocaine infusions in these mice (data not shown); a two-way ANOVA (treatment $X$ day) revealed a significant main effect of treatment $\left(F_{(1,8)}=5.4\right.$, $p=0.048)$, but no significant effect of day $\left(F_{(1,8)}=2.8, p=\right.$ $0.136)$ or treatment $\times$ day interaction $(F<1)$ for days $1-6$, and no difference on the shortened day 7 (independent-samples $t$ test: $\left.t_{(8)}=1.9, p=0.090\right)$.

Vehicle- and PD325901-administered mice differed in cocaine intake following intra-NAc administration. Figure $9 \mathrm{~A}$ shows the mean ( \pm SEM) number of cocaine infusions received during $9 \mathrm{~d}$ of cocaine SA, with intra-NAc administration of PD325901 or vehicle conducted 30 min before the session on day 7. A two-way ANOVA (treatment $\times$ day) of days 1-6 revealed no difference between PD325901 or vehicle groups before intra-NAc microinjections ( $F$ values $<1$ except day: $F_{(5,85)}=13.2, p<$ $0.0005)$. Independent-samples $t$ tests of the number of cocaine 
A

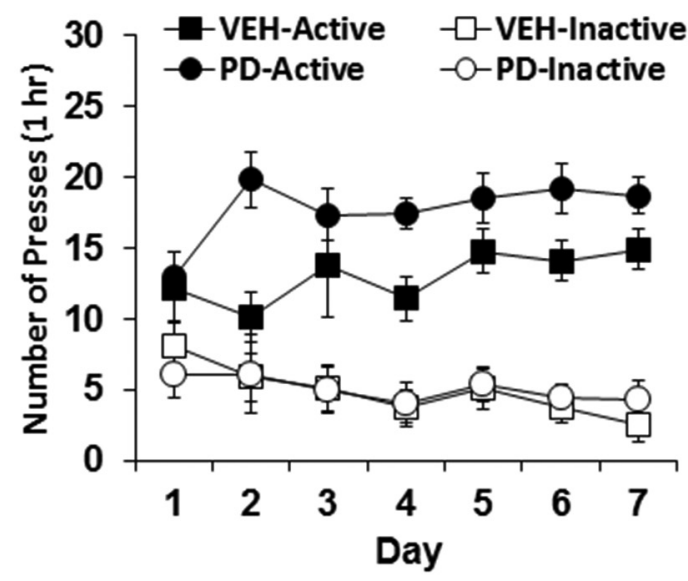

C

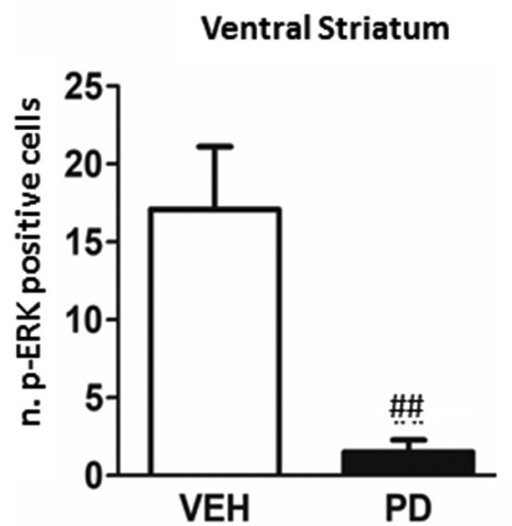

D
B

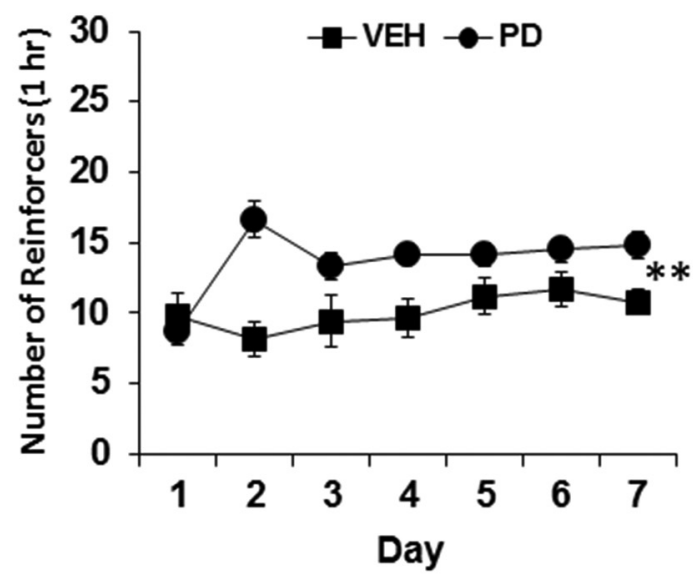

E
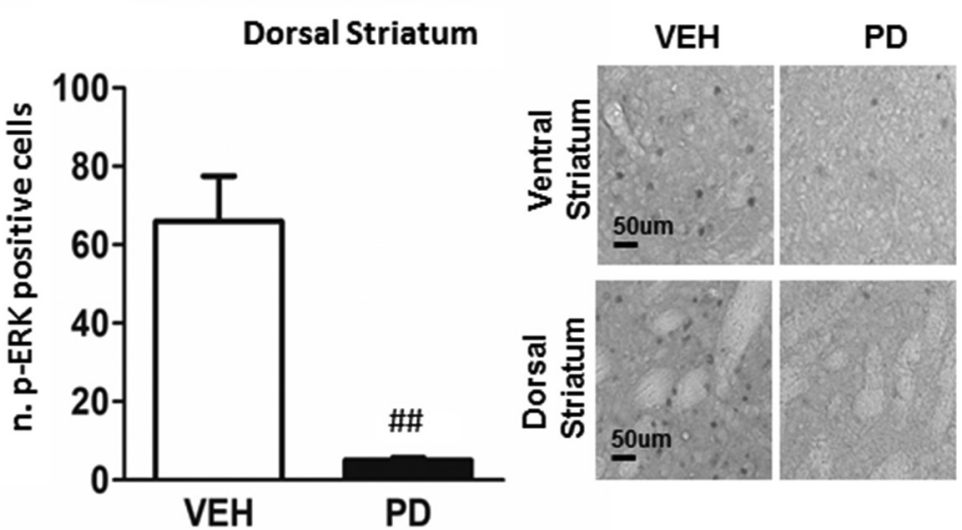

Figure 8. PD325901 administered intraperitoneally increased cocaine intake and decreased pERK. A, Mice treated with intraperitoneal vehicle $(\mathrm{VEH} ; n=9)$ or PD325901 (PD, $10 \mathrm{mg} / \mathrm{kg} ; n=11)$ before daily cocaine SA sessions did not differ significantly in lever responding. Data represent mean ( \pm SEM) number of presses on the active and inactive levers during 7 daily $1 \mathrm{~h} \mathrm{sessions} \mathrm{of} \mathrm{cocaine}$ $S A(0.50 \mathrm{mg} / \mathrm{kg} / 14 \mu$ infusion). $\boldsymbol{B}$, The number of cocaine reinforcers achieved differed significantly between the groups across daily sessions, with the PD group earning more reinforcers than the VEH group. Data represent mean ( \pm SEM) number of reinforcers achieved during 7 daily $1 \mathrm{~h}$ cocaine SA sessions $(0.50 \mathrm{mg} / \mathrm{kg} / 14 \mu \mathrm{l}$ infusion). PD325901 $(n=5)$ decreased the number of pERK1/2-positive cells relative to vehicle $(n=5)$ in both the (C) VS and ( $\boldsymbol{D})$ DS following pretreatment before 7 daily cocaine SA sessions. Data represent mean ( \pm SEM) number of pERK1/2-positive cells in each condition. $E$, Representative slices showing pERK-positive cells from the VS and DS of C57BL6N mice that received vehicle or PD325901. Mice were killed for immunohistochemistry on day 7 of $S A, 30$ min following the first injection of cocaine. ${ }^{* *} p<0.005$, main effect of treatment. ${ }^{\# \#} p=0.005$.

infusions received on days 7-9 indicate that PD325901-injected mice showed a decrease in cocaine intake relative to vehicletreated mice on day $8\left(t_{(17)}=2.8, p=0.012\right)$, but not day 7 or day $9\left(\right.$ day $7: t_{(17)}=1.1, p=0.290$; day 9: $\left.t_{(17)}=1.3, p=0.228\right)$. Figure 9 (inset) shows a representative image from a cannulamounted mouse showing dye injected into the cannula tract in the NAc.

Vehicle- and PD325901-administered mice did not differ in cocaine intake following intra-DS administration. Figure $9 B$ shows the mean ( \pm SEM) number of cocaine infusions received during $9 \mathrm{~d}$ of cocaine SA, with intra-DS administration of PD325901 or vehicle conducted 30 min before the session on day 7. A two-way ANOVA (treatment $\times$ day) of days $1-6$ revealed no difference between PD325901 and vehicle groups before intra-DS microinjections $(F$ values $<1)$. Independent-samples $t$ tests of the number of cocaine infusions received on days 7-9 indicate that PD325901- and vehicle-treated mice showed no difference in cocaine intake on any of the 3 days (day $7: t_{(11)}=0.1, p=0.891$; day 8: $t_{(11)}=1.3, p=0.237$; day 9: $\left.t_{(11)}=0.7, p=0.525\right)$. Figure 9 (inset) shows a representative image from a cannula-mounted mouse showing dye injected into the cannula tract in the DS.
These data confirm somewhat our previous findings in RasGRF2 KO mice and LV-RasGRF2-shRNA mice. Consistent with the RasGRF2 KO line, peripheral PD325901 resulted in an increase in cocaine SA, suggesting that general, or systemic, alterations in Ras-ERK signaling may result in a decrement in cocaine reward that is overcome by increasing cocaine intake. Consistent with our findings with LV-RasGRF2-shRNA in mice, PD325901 administered into the NAc reduced cocaine intake, albeit temporarily, suggesting that focused Ras-ERK inhibition may decrease cocaine reward.

\section{Discussion}

Here we sought to extend the understanding of the role of the Ras-ERK pathway in general, and RasGRF1 and RasGRF2 more specifically, in drug-mediated behaviors using operant responding for cocaine in mice. Cocaine SA resulted in an increase in pERK1/2- and pAcH3-positive cells in both the VS and DS relative to controls. RasGRF2 KO mice demonstrated an increase in cocaine SA, whereas RasGRF1 KO in mice had no effect, suggesting that RasGRF2 is more relevant to the primary reinforcing properties of cocaine than RasGRF1. Increases in pERK1/2- and 
A

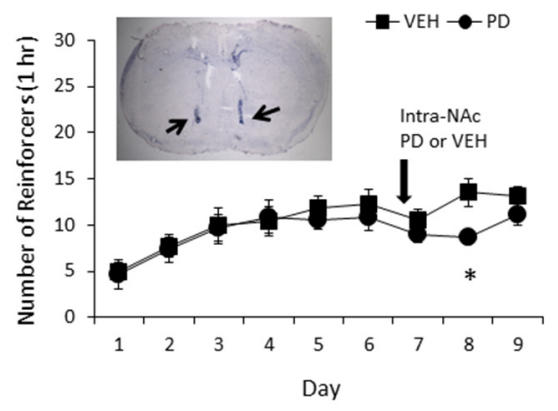

B

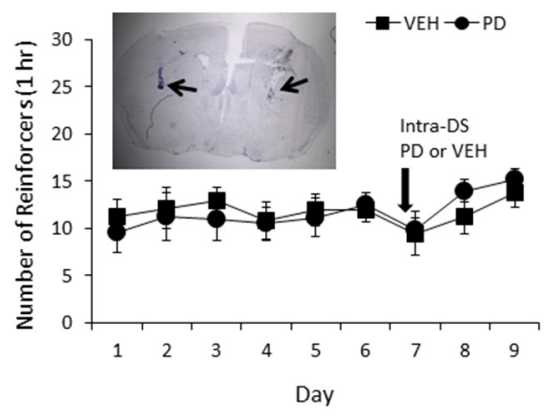

Figure 9. Intra-NAC, but not intra-DS, PD325901 decreased cocaine intake. $A$, The number of cocaine reinforcers achieved differed between groups administered vehicle (VEH; $n=10$ ) or PD325901 (PD; $n=9$ ) into the NAc only on day 8, with the PD325901 group earning less reinforcers than the vehicle group. Data represent mean $( \pm$ SEM) number of reinforcers achieved during 9 daily $1 \mathrm{~h}$ cocaine SA sessions $(0.50 \mathrm{mg} / \mathrm{kg} / 14 \mu \mathrm{l}$ infusion). PD325901 (5 $\mathrm{ng} / 0.5 \mu \mathrm{l} /$ side) or vehicle was administered into the NAc $30 \mathrm{~min}$ before the day $7 \mathrm{SA}$ session. Inset, A representative image from a cannula-mounted mouse showing dye injected into the cannula tract in the NAc. Black arrows indicate location of catheter tip. $\boldsymbol{B}$, The number of cocaine reinforcers achieved differed between groups administered vehicle (VEH; $n=6$ ) or PD325901 (PD; $n=7$ ) into the DS only on day 8 , with the PD325901 group earning less reinforcers than the vehicle group. Data represent mean ( \pm SEM) number of reinforcers achieved during 9 daily $1 \mathrm{~h}$ cocaine SA sessions ( $0.50 \mathrm{mg} / \mathrm{kg} / 14 \mu \mathrm{l}$ infusion). PD325901 ( $5 \mathrm{ng} / 0.5 \mu \mathrm{l} / \mathrm{side}$ ) or vehicle was administered into the DS 30 min before the day 7 SA session. Inset, A representative image from a cannula-mounted mouse showing dye injected into the cannula tract in the DS. Black arrows indicate location of catheter tip. ${ }^{*} p<0.05$.

pAcH3-positive cells in the VS and DS resulting from cocaine SA in WT mice were absent in RasGRF2 KO mice, suggesting an important role of the Ras-ERK signaling cascade in cocaine reinforcement during cocaine SA. Finally, microinjection of LVRasGRF2-shRNA, but not LV-RasGRF1-shRNA, into both the NAc and DS reduced cocaine intake during SA relative to LVscrambled-shRNA controls, although this effect was opposite to that seen in RasGRF2 KO mice. Importantly, daily presession peripheral administration of the MEK inhibitor PD325901 replicated both the behavioral and molecular effects demonstrated in RasGRF2 KO mice, increasing cocaine intake and decreasing pERK1/2 expression during SA. In contrast, intra-NAc administration of PD325901 resulted in a similar decrease in cocaine intake to that demonstrated following LV-RasGRF2-shRNA administration, albeit only temporarily, whereas intra-DS PD325901 had no effect. These data suggest that RasGRF2 plays an important role in cocaine reward in mice that can be differentiated on the global and more focal levels.

Our demonstration of an increase in the number of pERK1/ 2-positive cells in both the DS and VS in response to cocaine relative to controls is consistent with other studies demonstrating pERK activation following acute and repeated peripheral injections of cocaine (Valjent et al., 2004; Papale et al., 2016). Further- more, the increase in the number of pAcH3-positive cells in both the VS and DS is consistent with increases in the expression of pERK1/2. Histone H3 is a nuclear ERK substrate activated by mitogen and stress-activated protein kinase 1 (MSK1) that has been linked to the transcriptional activation of immediate early genes, such as c-fos (Thomson et al., 1999; Clayton and Mahadevan, 2003), which have been demonstrated to be critical to the enduring plasticity associated with drugs of abuse (Berke and Hyman, 2000; Chandra and Lobo, 2017). Following activation in the cytoplasm, pERK translocates to the nucleus, where it activates MSK1, which subsequently phosphorylates histone $\mathrm{H} 3$ (Brami-Cherrier et al., 2009). The findings of increased pERK1/2 and $\mathrm{pAcH} 3$ are consistent with a role for the Ras-ERK pathway in the striatum in cocaine SA.

Cocaine SA in RasGRF2 KO mice resulted in an increase in $\mathrm{SA}$ relative to WT mice. In contrast, cocaine SA was not affected in RasGRF1 KO mice, suggesting dissociation between the actions of RasGRF1 and RasGRF2 on cocaine reward. Previous work has demonstrated both impaired conditioned sensitization and CPP in response to cocaine in RasGRF1 KO mice relative to controls (Fasano et al., 2009). These data suggest that RasGRF2 is more relevant for cocaine reward, whereas RasGRF1 may mediate conditioned responding following the learning of associations between cocaine and cocaine-associated cues and environments.

The increase in cocaine SA in RasGRF2 KO mice likely reflects a decrease in the magnitude of the cocaine reinforcer, requiring an increase in cocaine intake to achieve a similar putative subjective effect, similar to that demonstrated following a reduction in the dose of cocaine (e.g., Thomsen and Caine, 2006). This effect is similar to that seen with peripheral injections of dopamine D1receptor (D1R) antagonists. The D1R antagonist SCH-23390 has been consistently demonstrated to increase cocaine SA when administered systemically (Haile and Kosten, 2001; Caine et al., 2007) in rodents. Previous research has specifically implicated D1R-mediated signaling (Valjent et al., 2000; Zhang et al., 2004; Bertran-Gonzalez et al., 2008), in concert with NMDA receptor activation (Jiao et al., 2007; Ren et al., 2010), via subsequent Ras-ERK activation as a critical factor in the regulation of cocaine-dependent synaptic plasticity in the striatum (Girault et al., 2007; Cerovic et al., 2013). In addition to a clear postsynaptic role for Ras-ERK signaling resulting from dopaminergic activity, RasGRF2 has also been identified as part of the proteome of the dopamine transporter (Maiya et al., 2007), suggesting a potential presynaptic role for RasGRF2, such as influencing DA release (Bloch-Shilderman et al., 2001).

Our pERK1/2 data in the RasGRF2 line confirm the likelihood that RasGRF2 mediates its effects via the Ras-ERK pathway. RasGRF2 KO mice did not show the increase in pERK1/2-positive cells in the VS and DS demonstrated in WT littermates and in our first experiment, a likely mechanistic explanation for the increase in SA demonstrated in RasGRF2 KO mice. The increased pAcH3 outlined in the first experiment was also replicated in RasGRF2 WT controls but absent in RasGRF2 KO mice. These findings further implicate this ERK substrate in cocaine SA in mice. Previous studies in mice have demonstrated that an acute injection of cocaine resulted in an increase in pAcH3 (Brami-Cherrier et al., 2005; Bertran-Gonzalez et al., 2008), an effect not present in MSK1 KO mice (Brami-Cherrier et al., 2005), which also lacked a c-Fos response, and impaired when preceded by the MEK inhibitor PD325901 (Papale et al., 2016). Our findings suggest that the inhibition of a cocaine-induced increase in $\mathrm{pAcH} 3$ is at least in part mediated through the Ras-ERK pathway via RasGRF2. 
In contrast to our findings in RasGRF2 $\mathrm{KO}$ mice, cocaine intake decreased following microinjection of LV-RasGRF2shRNA into the NAc relative to LV-scrambled-shRNA. It is not entirely clear why the response to cocaine differed in these animals, but may result from a focal knockdown of RasGRF2, in contrast to the global disruption of RasGRF2 in KO animals. Indeed, it has been previously hypothesized that the KO of RasGRF2 in mice resulted in a reduced excitability of VTA DA neurons and subsequent generalized disruption of dopaminergic signaling, which caused a reduction in alcohol consumption in RasGRF2 KO mice relative to controls (Stacey et al., 2012). This hypothesis is consistent with the alteration in basal extracellular DA levels demonstrated in RasGRF2 KO mice (Stacey et al., 2012). In terms of the studies reported here, a disruption in dopaminergic signaling may have resulted in a minor decrease in cocaine reward that was overcome by increased cocaine intake. In contrast, knockdown of RasGRF2 in the NAc likely resulted in a focused, disruptive effect in a brain region that specifically mediates putative cocaine reward (Wise and Bozarth, 1985; Koob and Volkow, 2010). For example, previous studies have demonstrated that minor decreases in cocaine reward result in compensatory increases in cocaine intake, whereas further decreases result in a reduction of intake (De Wit and Wise, 1977; Ettenberg et al., 1982; Caine and Koob, 1994). These divergent findings may implicate brain areas outside of the striatum in the effects of the RasGRF2 KO on cocaine reward. As already mentioned, RasGRF2 may play an important role on DAT-containing neurons (Bloch-Shilderman et al., 2001). Nonetheless, our data confirm that RasGRF2 is involved in cocaine reward during SA. In contrast, LV-RasGRF1-shRNA administration had no effect on cocaine SA relative to LV-scrambled-shRNA controls, consistent with our findings in RasGRF1 KO mice.

Interestingly, microinjection of LV-RasGRF2-shRNA into the DS also resulted in a decrease in cocaine intake. Beyond its wellknown role in the control of habitual behavior following extensive drug-taking (Everitt and Robbins, 2005; Pierce and Vanderschuren, 2010), some previous research has also indicated a role for the DS in the acute reinforcing properties of cocaine. For example, the magnitude of the dopaminergic response to self-administered cocaine in drug-naive rats was shown to be similar in the NAc and DS (D'Souza and Duvauchelle, 2006). In addition, Veeneman et al. (2012) demonstrated that the DA receptor antagonist $\alpha$-flupenthixol administered into the dorsolateral striatum altered cocaine $\mathrm{SA}$ in rats, even after limited exposure (see also Kantak et al., 2002), and disconnection studies between the NAc shell and dorsolateral striatum with $\alpha$-flupenthixol demonstrated that these serial connections mediate cocaine reinforcement during early cocaine exposure (Veeneman et al., 2015). A role for the DS in cocaine reinforcement is consistent with our molecular results above, in which cocaine SA increased pERK activation in the DS in addition to the VS, effects impaired in KO mice. Further studies will need to clarify whether this effect of RasGRF2 inhibition is due to a serial connection between the VS and DS or results from another as yet unspecified role of the DS in cocaine SA.

Daily SA sessions preceded by administration of the MEK inhibitor PD325901 increased cocaine intake while simultaneously decreasing pERK1/2 levels in the VS and DS. These findings replicated those seen in RasGRF2 KO mice, suggesting that RasGRF2 exerts its effects via the Ras-ERK signaling cascade and confirming the likelihood that a global inhibition of Ras-ERK signaling may result in a loss in cocaine reward that is overcome by a compensatory increased intake. In terms of cocaine, few, if any, studies have demonstrated alterations in cocaine intake specifically during SA resulting from the inhibition of activity of components of the Ras-ERK signaling pathway, such as impairment of MEK (but see Miszkiel et al., 2014). However, numerous previous studies have demonstrated the involvement of MEK, and the subsequent activity of ERK, in other cocaine-related behaviors, such as CPP (e.g., Valjent et al., 2000; Miller and Marshall, 2005; Papale et al., 2016), which support an inhibitory role of Ras-ERK signaling blockade on cocaine reward. For example, we previously demonstrated that PD325901 administered before a test for cocaine CPP resulted in the long-term inhibition of CPP and a complete attenuation of an acute cocaine-induced increase in pERK1/2 in the VS (Papale et al., 2016). SL327, like PD325901, one of only a few available blood-brain barrier penetrating MEK inhibitors, was also shown to increase alcohol SA in mice when administered before daily sessions (Faccidomo et al., 2009) and was interpreted as a compensatory increase in responding due to a decrease in alcohol reward. In addition, RasGRF2 KO mice have previously been shown to demonstrate a loss in alcohol-induced dopamine increase in the NAc and DS (Stacey et al., 2012), suggesting a reduction in alcohol reinforcement and consistent with a modulatory role of the Ras-ERK pathway in drug-mediated behaviors.

The site-specific administration of PD325901 into the NAc, but not DS, resulted in a decrease in cocaine intake. PD administered into the NAc failed to have an immediate effect, but during the next session on day 8 resulted in a temporary decrease in cocaine intake that was no longer significant on day 9. A lack of effect on day 7 is not surprising given that the relatively stressful injection procedures likely masked any potential differences between the groups. The decrease in intake the following day is consistent with the pharmacokinetics of PD325901, which showed $50 \%$ inhibition of pERK at $\sim 24 \mathrm{~h}$ in rodent brain at the dose used in the current study (Iverson et al., 2009). Furthermore, this effect is consistent with the decrease in cocaine intake following LV-RasGRF2-shRNA, again suggesting that an NAcspecific inhibition of Ras-ERK signaling resulted in an impairment in cocaine SA. That PD325901 had no effect on cocaine intake may be surprising given that LV-RasGRF2-shRNA in the DS resulted in a reduction in intake similar to that seen with LV-RasGRF2-shRNA in the NAc. As noted above, several studies have suggested a role for the DS in cocaine reward during early exposure, and RasGRF2 knockdown before cocaine SA in mice may have inhibited the acquisition of SA, whereas MEK inhibition at a single administration after several days of SA failed to affect the maintenance of cocaine SA. However, further disentanglement of the specific role of RasGRF2 in the DS during cocaine $\mathrm{SA}$ is required.

In conclusion, we used a combination of molecular, pharmacological, and lentiviral techniques to demonstrate that RasGRF2, but not RasGRF1, is involved in cocaine reinforcement associated with operant SA. These studies further implicate the role of the Ras-ERK pathway in the effects of drugs of abuse and indicate that RasGRF2 may be a risk factor in the cocaine use that may ultimately lead to dependence in humans.

\section{References}

Ben Hamida S, Neasta J, Lasek AW, Kharazia V, Zou M, Carnicella S, Janak PH, Ron D (2012) The small G protein H-ras in the mesolimbic system is a molecular gateway to alcohol-seeking and excessive drinking behaviors. J Neurosci 32:15849-15858.

Berke JD, Hyman SE (2000) Addiction, dopamine, and the molecular mechanisms of memory. Neuron 25:515-532.

Bernardi RE, Spanagel R (2013) The ClockDelta19 mutation in mice fails to 
alter the primary and secondary reinforcing properties of nicotine. Drug Alcohol Depend 133:733-739.

Bernardi RE, Broccoli L, Hirth N, Justice NJ, Deussing JM, Hansson AC, Spanagel R (2017) Dissociable role of corticotropin releasing hormone receptor subtype 1 on dopaminergic and D1 dopaminoceptive neurons in cocaine seeking behavior. Front Behav Neurosci 11:221.

Bertran-Gonzalez J, Bosch C, Maroteaux M, Matamales M, Hervé D, Valjent E, Girault JA (2008) Opposing patterns of signaling activation in dopamine D1 and D2 receptor-expressing striatal neurons in response to cocaine and haloperidol. J Neurosci 28:5671-5685.

Bido S, Solari N, Indrigo M, D’Antoni A, Brambilla R, Morari M, Fasano S (2015) Differential involvement of ras-GRF1 and ras-GRF2 in L-DOPAinduced dyskinesia. Ann Clin Transl Neurol 2:662-678.

Bloch-Shilderman E, Jiang H, Abu-Raya S, Linial M, Lazarovici P (2001) Involvement of extracellular signal-regulated kinase (ERK) in pardaxininduced dopamine release from PC12 cells. J Pharmacol Exp Ther 296:704-711.

Boguski MS, McCormick F (1993) Proteins regulating ras and its relatives. Nature 366:643-654.

Brambilla R, Gnesutta N, Minichiello L, White G, Roylance AJ, Herron CE, Ramsey M, Wolfer DP, Cestari V, Rossi-Arnaud C, Grant SG, Chapman PF, Lipp HP, Sturani E, Klein R (1997) A role for the ras signalling pathway in synaptic transmission and long-term memory. Nature 390: 281-286.

Brami-Cherrier K, Valjent E, Hervé D, Darragh J, Corvol JC, Pages C, Arthur SJ, Simon AJ,Girault JA, Caboche J (2005) Parsing molecular and behavioral effects of cocaine in mitogen- and stress-activated protein kinase-1-deficient mice. J Neurosci 25:11444-11454.

Brami-Cherrier K, Roze E, Girault JA, Betuing S, Caboche J (2009) Role of the ERK/MSK1 signalling pathway in chromatin remodelling and brain responses to drugs of abuse. J Neurochem 108:1323-1335.

Caine SB, Koob GF (1994) Effects of dopamine D-1 and D-2 antagonists on cocaine self-administration under different schedules of reinforcement in the rat. J Pharmacol Exp Ther 270:209-218.

Caine SB, Thomsen M, Gabriel KI, Berkowitz JS, Gold LH, Koob GF, Tonegawa S, Zhang J, Xu M (2007) Lack of self-administration of cocaine in dopamine D1 receptor knock-out mice. J Neurosci 27:13140-13150.

Cerovic M, d'Isa R, Tonini R, Brambilla R (2013) Molecular and cellular mechanisms of dopamine-mediated behavioral plasticity in the striatum. Neurobiol Learn Mem 105:63-80.

Chandra R, Lobo MK (2017) Beyond neuronal activity markers: select immediate early genes in striatal neuron subtypes functionally mediate psychostimulant addiction. Front Behav Neurosci 11:112.

Clayton AL, Mahadevan LC (2003) MAP kinase-mediated phosphoacetylation of histone $\mathrm{H} 3$ and inducible gene regulation. FEBS Lett 546:51-58.

Cox AD, Der CJ (2010) Ras history: the saga continues. Small GTPases 1:227.

Damez-Werno DM, Sun H, Scobie KN, Shao N, Rabkin J, Dias C, Calipari ES, Maze I, Pena CJ, Walker DM, Cahill ME, Chandra R, Gancarz A, Mouzon E, Landry JA, Cates H, Lobo MK, Dietz D, Allis CD, Guccione E, et al. (2016) Histone arginine methylation in cocaine action in the nucleus accumbens. Proc Natl Acad Sci U S A 113:9623-9628.

De Wit H, Wise RA (1977) Blockade of cocaine reinforcement in rats with the dopamine receptor blocker pimozide, but not with the noradrenergic blockers phentolamine or phenoxybenzamine. Can J Psychol 31:195-203.

D'Souza MS, Duvauchelle CL (2006) Comparing nucleus accumbens and dorsal striatal dopamine responses to self-administered cocaine in naive rats. Neurosci Lett 408:146-150.

Ettenberg A, Pettit HO, Bloom FE, Koob GF (1982) Heroin and cocaine intravenous self-administration in rats: mediation by separate neural systems. Psychopharmacology (Berl) 78:204-209.

Everitt BJ, Robbins TW (2005) Neural systems of reinforcement for drug addiction: from actions to habits to compulsion. Nat Neurosci 8:14811489.

Faccidomo S, Besheer J, Stanford PC, Hodge CW (2009) Increased operant responding for ethanol in male $\mathrm{C} 57 \mathrm{BL} / 6 \mathrm{~J}$ mice: specific regulation by the ERK1/2, but not JNK, MAP kinase pathway. Psychopharmacology (Berl) 204:135-147.

Farnsworth CL, Freshney NW, Rosen LB, Ghosh A, Greenberg ME, Feig LA (1995) Calcium activation of ras mediated by neuronal exchange factor ras-GRF. Nature 376:524-527.

Fasano S, D’Antoni A, Orban PC, Valjent E, Putignano E, Vara H, Pizzorusso
T, Giustetto M, Yoon B, Soloway P, Maldonado R, Caboche J, Brambilla R (2009) Ras-guanine nucleotide-releasing factor 1 (Ras-GRF1) controls activation of extracellular signal-regulated kinase (ERK) signaling in the striatum and long-term behavioral responses to cocaine. Biol Psychiatry 66:758-768.

Ferguson SM, Fasano S, Yang P, Brambilla R, Robinson TE (2006) Knockout of ERK1 enhances cocaine-evoked immediate early gene expression and behavioral plasticity. Neuropsychopharmacology 31:2660-2668.

Fernández-Medarde A, Esteban LM, Núñez A, Porteros A, Tessarollo L, Santos E (2002) Targeted disruption of ras-Grf2 shows its dispensability for mouse growth and development. Mol Cell Biol 22:2498-2504.

Girault JA, Valjent E, Caboche J, Hervé D (2007) ERK2: a logical AND gate critical for drug-induced plasticity? Curr Opin Pharmacol 7:77-85.

Grewal SS, York RD, Stork PJ (1999) Extracellular-signal-regulated kinase signalling in neurons. Curr Opin Neurobiol 9:544-553.

Haile CN, Kosten TA (2001) Differential effects of D1- and D2-like compounds on cocaine self-administration in Lewis and Fischer 344 inbred rats. J Pharmacol Exp Ther 299:509-518.

Indrigo M, Papale A, Orellana D, Brambilla R (2010) Lentiviral vectors to study the differential function of ERK1 and ERK2 MAP kinases. Methods Mol Biol 661:205-220.

Iverson C, Larson G, Lai C, Yeh LT, Dadson C, Weingarten P, Appleby T, Vo T, Maderna A, Vernier JM, Hamatake R, Miner JN, Quart B (2009) RDEA119/BAY 869766: a potent, selective, allosteric inhibitor of MEK1/2 for the treatment of cancer. Cancer Res 69:6839-6847.

Jiao H, Zhang L, Gao F, Lou D, Zhang J, Xu M (2007) Dopamine D (1) and D (3) receptors oppositely regulate NMDA- and cocaine-induced MAPK signaling via NMDA receptor phosphorylation. J Neurochem 103:840848.

Jin SX, Feig LA (2010) Long-term potentiation in the CA1 hippocampus induced by NR2A subunit-containing NMDA glutamate receptors is mediated by ras-GRF2/Erk map kinase signaling. PLoS One 5:e11732.

Kantak KM, Black Y, Valencia E, Green-Jordan K, Eichenbaum HB (2002) Stimulus-response functions of the lateral dorsal striatum and regulation of behavior studied in a cocaine maintenance/cue reinstatement model in rats. Psychopharmacology (Berl) 161:278-287.

Koob GF, Volkow ND (2010) Neurocircuitry of addiction. Neuropsychopharmacology 35:217-238.

Lu L, Hope BT, Dempsey J, Liu SY, Bossert JM, Shaham Y (2005) Central amygdala ERK signaling pathway is critical to incubation of cocaine craving. Nat Neurosci 8:212-219.

Maiya R, Ponomarev I, Linse KD, Harris RA, Mayfield RD (2007) Defining the dopamine transporter proteome by convergent biochemical and in silico analyses. Genes Brain Behav 6:97-106.

Mandalà M, Merelli B, Massi D (2014) Nras in melanoma: targeting the undruggable target. Crit Rev Oncol Hematol 92:107-122.

Mazzucchelli C, Brambilla R (2000) Ras-related and MAPK signalling in neuronal plasticity and memory formation. Cell Mol Life Sci 57:604-611.

Miller CA, Marshall JF (2005) Molecular substrates for retrieval and reconsolidation of cocaine-associated contextual memory. Neuron 47:873884 .

Miszkiel J, Detka J, Cholewa J, Frankowska M, Nowak E, Budziszewska B, Przegalinski E, Filip M (2014) The effect of active and passive intravenous cocaine administration on the extracellular signal-regulated kinase (ERK) activity in the rat brain. Pharmacol Rep 66:630-637.

Olevska A (2016) The role of Ras guanine nucleotide releasing factors in cocaine-mediated behaviors. PhD thesis. Ruperto-Carola University of Heidelberg, Heidelberg, Germany.

Pamonsinlapatham P, Hadj-Slimane R, Lepelletier Y, Allain B, Toccafondi M, Garbay C, Raynaud F (2009) p120-ras GTPase activating protein (RasGAP): a multi-interacting protein in downstream signaling. Biochimie 91:320-328.

Papale A, Brambilla R (2014) Viral vector approaches in neurobiology and brain diseases. New York: Humana.

Papale A, Morella IM, Indrigo MT, Bernardi RE, Marrone L, Marchisella F, Brancale A, Spanagel R, Brambilla R, Fasano S (2016) Impairment of cocaine-mediated behaviours in mice by clinically relevant Ras-ERK inhibitors. Elife 5:e17111.

Parelkar NK, Jiang Q, Chu XP, Guo ML, Mao LM, Wang JQ (2009) Amphetamine alters ras-guanine nucleotide-releasing factor expression in the rat striatum in vivo. Eur J Pharmacol 619:50-56. 
Paxinos G, Franklin KB (2004) The mouse brain in stereotaxic coordinates, Ed 2. London: Academic.

Pierce RC, Vanderschuren LJ (2010) Kicking the habit: the neural basis of ingrained behaviors in cocaine addiction. Neurosci Biobehav Rev 35:212-219.

Ren Z, Sun WL, Jiao H, Zhang D, Kong H, Wang X, Xu M (2010) Dopamine D1 and N-methyl-D-aspartate receptors and extracellular signalregulated kinase mediate neuronal morphological changes induced by repeated cocaine administration. Neuroscience 168:48-60.

Roberts PJ, Der CJ (2007) Targeting the raf-MEK-ERK mitogen-activated protein kinase cascade for the treatment of cancer. Oncogene 26: 3291-3310.

Schumann G, Coin LJ, Lourdusamy A, Charoen P, Berger KH, Stacey D, Desrivières S, Aliev FA, Khan AA, Amin N, Aulchenko YS, Bakalkin G, Bakker SJ, Balkau B, Beulens JW, Bilbao A, de Boer RA, Beury D, Bots ML, Breetvelt EJ, et al. (2011) Genome-wide association and genetic functional studies identify autism susceptibility candidate 2 gene (AUTS2) in the regulation of alcohol consumption. Proc Natl Acad Sci U S A 108:7119-7124.

Stacey D, Bilbao A, Maroteaux M, Jia T, Easton AC, Longueville S, Nymberg C, Banaschewski T, Barker GJ, Büchel C, Carvalho F, Conrod PJ, Desrivières $\mathrm{S}$, Fauth-Bühler $\mathrm{M}$, Fernández-Medarde $\mathrm{A}$, Flor H, Gallinat J, Garavan H, Bokde AL, Heinz A, et al. (2012) RASGRF2 regulates alcohol-induced reinforcement by influencing mesolimbic dopamine neuron activity and dopamine release. Proc Natl Acad Sci U S A 109:2112821133.

Stacey D, Lourdusamy A, Ruggeri B, Maroteaux M, Jia T, Cattrell A, Nymberg C, Banaschewski T, Bhattacharyya S, Band H, Barker G, Bokde A, Buchel C, Carvalho F, Conrod P, Desrivieres S, Easton A, Fauth-Buehler M, FernándezMedarde A, Flor H, et al. (2016) A translational systems biology approach in both animals and humans identifies a functionally related module of accumbal genes involved in the regulation of reward processing and binge drinking in males. J Psychiatry Neurosci 41:192-202.
Takai Y, Sasaki T, Matozaki T (2001) Small GTP-binding proteins. Physiol Rev 81:153-208.

Thomsen M, Caine SB (2006) Cocaine self-administration under fixed and progressive ratio schedules of reinforcement: comparison of C57BL/6J, 129X1/SvJ, and 129S6/SvEvTac inbred mice. Psychopharmacology (Berl) 184:145-154.

Thomson S, Mahadevan LC, Clayton AL (1999) MAP kinase-mediated signalling to nucleosomes and immediate-early gene induction. Semin Cell Dev Biol 10:205-214.

Valjent E, Corvol JC, Pages C, Besson MJ, Maldonado R, Caboche J (2000) Involvement of the extracellular signal-regulated kinase cascade for cocaine-rewarding properties. J Neurosci 20:8701-8709.

Valjent E, Pagès C, Hervé D, Girault JA, Caboche J (2004) Addictive and non-addictive drugs induce distinct and specific patterns of ERK activation in mouse brain. Eur J Neurosci 19:1826-1836.

Veeneman MM, Broekhoven MH, Damsteegt R, Vanderschuren LJ (2012) Distinct contributions of dopamine in the dorsolateral striatum and nucleus accumbens shell to the reinforcing properties of cocaine. Neuropsychopharmacology 37:487-498.

Veeneman MM, Damsteegt R, Vanderschuren LJ (2015) The nucleus accumbens shell and the dorsolateral striatum mediate the reinforcing effects of cocaine through a serial connection. Behav Pharmacol 26: 193-199.

Wise RA, Bozarth MA (1985) Brain mechanisms of drug reward and euphoria. Psychiatr Med 3:445-460.

Zhang GC, Hoffmann J, Parelkar NK, Liu XY, Mao LM, Fibuch EE, Wang JQ (2007) Cocaine increases ras-guanine nucleotide-releasing factor 1 protein expression in the rat striatum in vivo. Neurosci Lett 427:117-121.

Zhang L, Lou D, Jiao H, Zhang D, Wang X, Xia Y, Zhang J, Xu M (2004) Cocaine-induced intracellular signaling and gene expression are oppositely regulated by the dopamine D1 and D3 receptors. J Neurosci 24: $3344-3354$. 